Review

\title{
HIV-1 and Its Resistance to Peptidic Carbohydrate-Binding Agents (CBAs): An Overview
}

\author{
Geoffrey Férir, Stephanie C. Gordts and Dominique Schols * \\ Laboratory of Virology and Chemotherapy, Rega Institute for Medical Research, \\ University of Leuven, Minderbroedersstraat 10. Leuven B-3000, Belgium; \\ E-Mails: Geoffrey.ferir@rega.kuleuven.be (G.F.); Stephanie.gordts@rega.kuleuven.be (S.C.G.) \\ * Author to whom correspondence should be addressed; \\ E-Mail: Dominique.schols@rega.kuleuven.be; Tel.: +32-16-337-352; Fax: +32-16-337-340.
}

External Editors: Els Van Damme and Kristof De Schutter

Received: 22 October 2014; in revised form: 4 December 2014 / Accepted: 8 December 2014/

Published: 15 December 2014

\begin{abstract}
The glycoproteins on the surfaces of enveloped viruses, such as HIV, can be considered as a unique target for antiviral therapy. Different carbohydrate-binding agents (CBAs) target specific glycans present on viral glycoproteins of enveloped viruses. It has been shown that long-term CBA pressure in vitro can result in mutant HIV-1 isolates with several $N$-linked glycan deletions on gp120. These studies demonstrated that mainly high-mannose type glycans are deleted. However, interestingly, N241, N262 and N356 on gp120 have never been found to be affected after prolonged CBA exposure. Here, we review the mutation and (cross)-resistance profiles of eleven specific generated CBA-resistant HIV-1 strains. We observed that the broad-neutralizing anti-carbohydrate binding mAb $2 \mathrm{G} 12$ became completely inactive against all the generated CBA-resistant HIV-1 clade B isolates. In addition, all of the CBAs discussed in this review, with the exception of NICTABA, interfered with the binding of $2 \mathrm{G} 12 \mathrm{mAb}$ to gp120 expressed on HIV-1-infected T cells. The cross-resistance profiles of mutant HIV-1 strains are varying from increased susceptibility to very high resistance levels, even among different classes of CBAs with dissimilar sugar specificities or binding moieties [e.g., $\alpha(1,3), \alpha(1,2), \alpha(1,6)]$. Recent studies demonstrated promising results in non-topical formulations (e.g., intranasally or subcutaneously), highlighting their potential for prevention (microbicides) and antiviral therapy.
\end{abstract}


Keywords: HIV; carbohydrate-binding agents; resistance; therapy; microbicide; $N$-linked glycans; deletions

\section{Introduction}

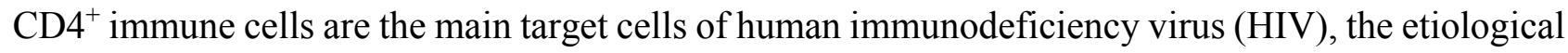
agent of acquired immune deficiency syndrome (AIDS). Infection starts when the viral envelope glycoproteins gp120 interact with the cellular CD4 receptors, present on T helper cells (Th cells), dendritic cells (DCs), monocytes and macrophages. The initial gp120/CD4 interaction induces a first set of conformational changes inside gp120 in order to gain subsequent binding with the cellular chemokine receptors CCR5 or CXCR4 for, respectively, CCR5-tropic (or R5) and CXCR4-tropic (or X4) HIV-1 strains. Upon these coreceptor interactions, a second set of conformational changes induce the exposure of gp41, which initiates membrane fusion by the formation of the six-helix-bundle, in combination with the host cell endocytic machinery $[1,2]$.

In this review, we focus on $N$-linked glycan structures, which are abundantly present on the surface of HIV-1 gp120. Gp120 is displayed as a trimer and each monomer consists of 5 variable regions (V1-V5) and 5 conserved domains (C1-C5), which are heavily glycosylated. These glycans account for $\sim 50 \%$ of its molecular mass $[3,4]$.

The synthesis of these glycans is beyond the scope of this review (see reference [5]). As the degree of glycosylation depends on the HIV subtypes and the host cell machinery, the number of glycosylation sites vary between 18 and 33. Structural characterization of the carbohydrates on gp120 by Mizuochi and coworkers indicated that the glycoprotein is unique in its degree of diversity of oligosaccharide structures, as it contains 33\% high-mannose type, 4\% hybrid type and 63\% of complex type sugars (Figure 1A) [6,7]. These complex types, which are more than $90 \%$ fucosylated and/or sialylated, could be further subdivided in 4 categories: mono- $(\sim 2 \%)$, bi- $(\sim 38 \%)$, tri- $(\sim 12 \%)$ and tetra-antennary $(\sim 10 \%)$ sugars. Leonard and colleagues studied the glycan structures on gp120 of HIV-1 strain IIIB and found 24 putative $N$-linked glycosylation sites (Table 1, Figures 1B and 2a). These sites are characterized by the sequon "N-X-S/T" (Asn-X-Ser/Thr) in the amino acid sequence of gp120, with $\mathrm{X}$ being any amino acid except proline (Figure 1). Eleven oligomannose (high-mannose) and/or hybrid type glycans were found and 13 of the complex type [3]. All have a common pentasaccharide core unit ( $\mathrm{Man}_{3} \mathrm{GlcNAc}_{2}$ ) linked to the amide side chain of asparagine (Figure 1A). However, the abovementioned percentages of various glycan types were derived from an analysis of recombinant monomeric gp120 [3,6,7]. Recent studies indicated that the glycan composition of trimeric gp120 on replication competent HIV virions (and pseudoviral particles) contains predominantly oligomannose glycans, independently of the cellular production system (e.g., PBMCs or cultured human HEK293T cells) and viral subtypes (e.g., subtypes A, B and C) [8,9]. As the HIV-1 resistance studies described in this review were performed in HIV-1 replication assays, the site-specific glycosylation assignments presented here most likely overestimate the complex glycan content. We therefore renamed them "potential" complex glycans (Table 1). Remarkably, despite using the host cell glycosylation machinery, the glycans on the HIV envelope glycoproteins are predominantly high-mannoses in contrast to the host cell glycoproteins [10]. 
Figure 1. (A) Examples of $N$-linked glycans present on gp120. (a) Oligomannose or high-mannose (Man9) type glycans, (b) hybrid type glycans, (c) tri- and (d) bi-antennary complex type glycans. $\mathrm{N}$ is asparagine; $\mathrm{X}$ is any amino acid except proline; $\mathrm{S}$ is serine and $\mathrm{T}$ is threonine. The abbreviations for the sugar units are: Fuc is fucose; Gal is galactose; GlcNAc is N-acetylglucosamine; Man is mannose and SA is sialic acid. The common pentasaccharide core unit is also marked in blue; (B) HIV-1 gp120 amino acid sequence and glycosylation sites. Alignment of the gp120 envelope protein sequences of the $\mathrm{T}$ cell line adapted HIV-1 strains IIIB and NL4.3. The N-glycosylation sites are shown in grey and the sequon numbers in red. The N397 glycan is not present in the viral strain we used due to the NSTWS sequence deletion as indicated in brackets. The N463 glycan is only present as N461 in our laboratory HIV-1 NL4.3 wild-type strain and not in the sequenced HIV-1 IIIB wild-type strain.

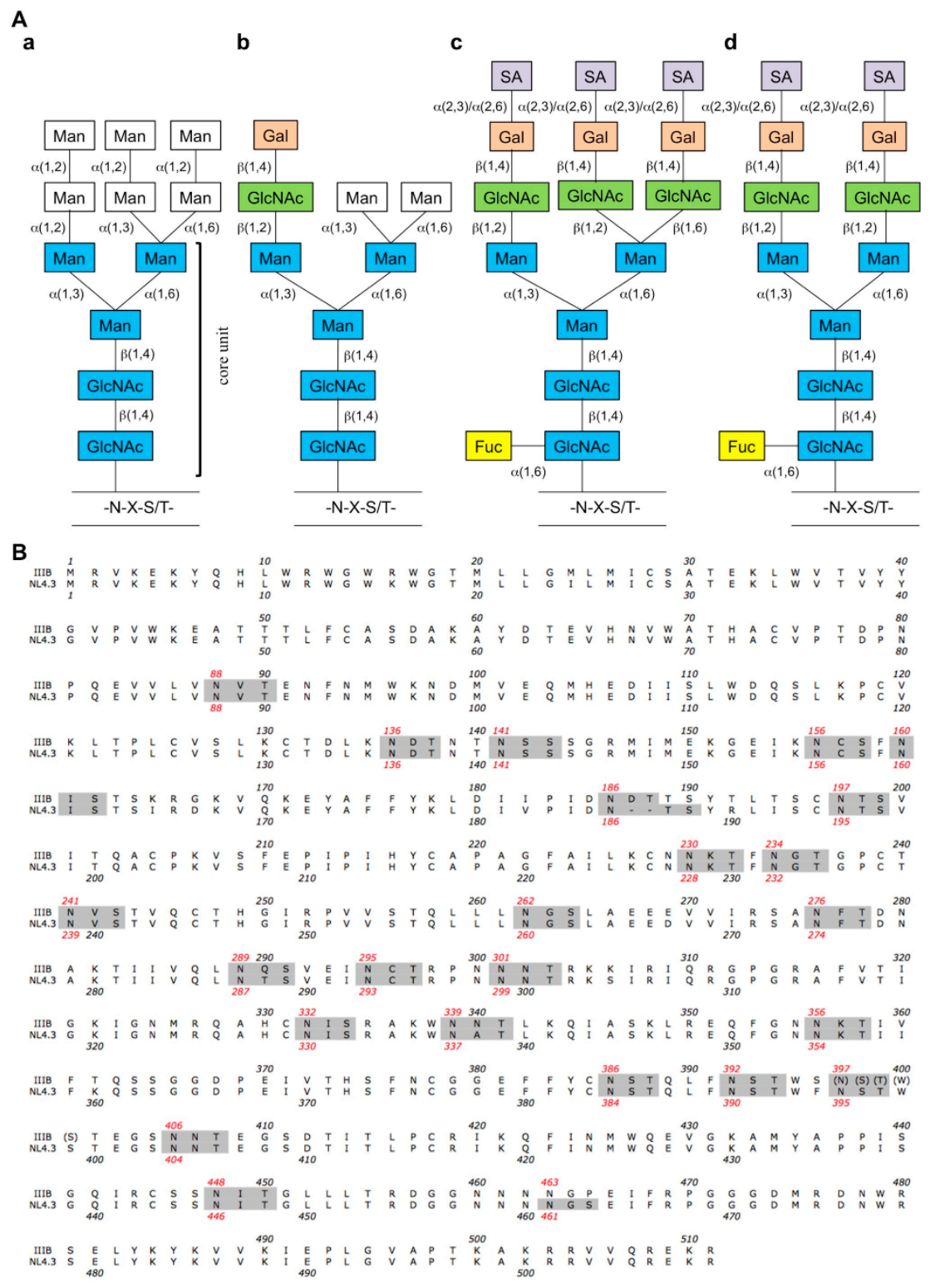


Figure 2. Positions of mutated $N$-linked glycans under selective CBA pressure. (a) Ribbon diagrams show the $24 \mathrm{~N}$-linked glycosylation sites in recombinant (monomeric) gp120 of wild-type HIV-1 IIIB according to Leonard et al. [3] and Kwong et al. [11]. The green dots indicate the high-mannose type glycans and the yellow dots the hybrid/"potential" complex types. Recent findings by Doores et al. [8] and Bonomelli et al. [9] demonstrated that the glycan composition of recombinant monomeric gp120 differs greatly from that of trimeric gp120 present on infectious viral particles, of which the latter were used in the described resistance studies. Based on these data, the specific glycosylation assignments presented here are an overestimate of complex glycan content. Positions of the glycans deleted on gp120 under increasing concentrations of the following CBAs: (b) 2G12 mAb (NL4.3), (c) 2G12 mAb (IIIB), (d) HHA (IIIB), (e) GNA (IIIB), (f) AH (IIIB), (g) CV-N (IIIB), (h) CV-N (NL4.3), (i) MVN (NL4.3), (j) BanLec (IIIB), (k) GRFT (IIIB) and (l) UDA (IIIB) are marked with red dots. Figure 2a, reproduced with permission, from reference [12].

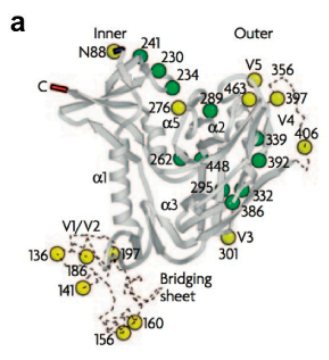

d
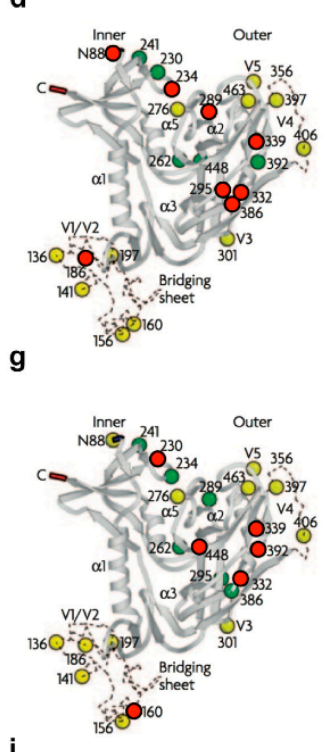

j

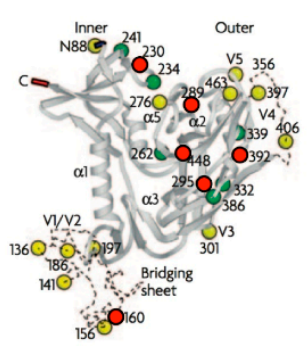

b

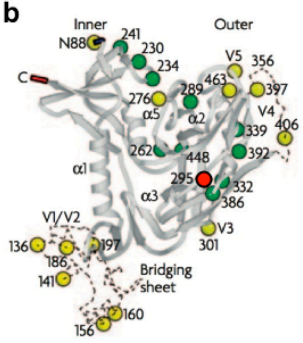

e

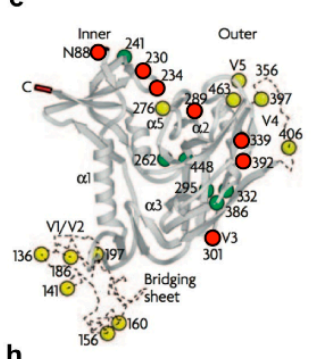

h

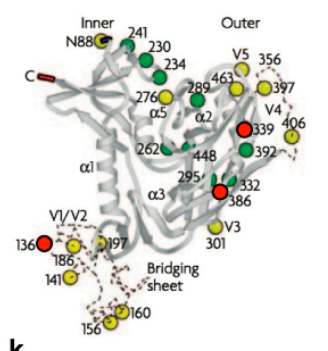

$\mathbf{k}$

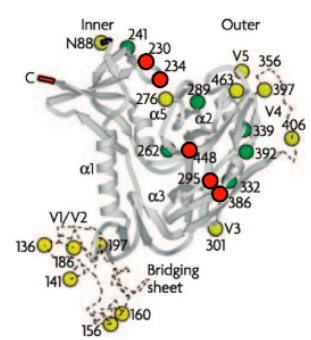

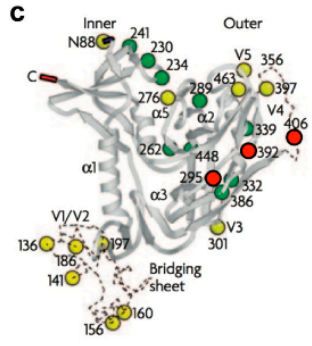

f

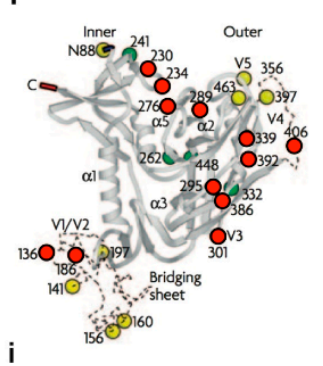

i

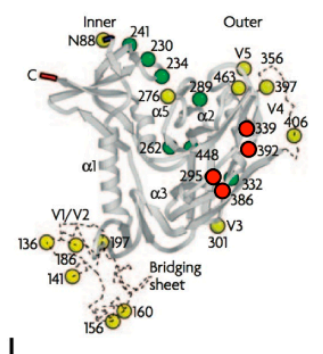

I

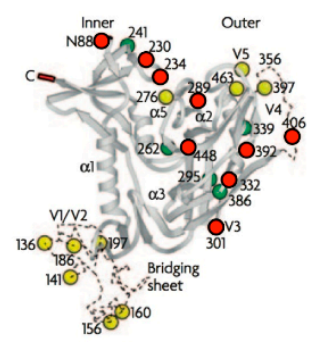


Table 1. Mutations in HIV-1 gp120 appearing under selective CBA pressure in T cell cultures.

\begin{tabular}{|c|c|c|c|c|c|c|c|c|c|c|c|c|}
\hline Sequon ${ }^{a}$ & N-glycan & NL4.3 ${ }^{2 \mathrm{G} 12 \text { res. }}$ & IIIB ${ }^{2 \mathrm{G} 12 \text { res. }}$ & IIIB ${ }^{\text {HHAres. }}$ & IIIB GNAres. & IIIB ${ }^{\text {AHres. }}$ & IIIB $^{\text {CV-Nres. }}$ & NL4.3 ${ }^{\mathrm{CV}-\mathrm{Nres}}$ & NL4.3 ${ }^{\text {MVNres. }}$ & IIIB $^{\text {BanLecres. }}$ & IIIB GRFTres. & IIIB UDAres. \\
\hline NVT (N88) & "potential" complex & & & $\mathrm{x}$ & $\mathrm{x}$ & & & & & & & $\mathrm{x}$ \\
\hline NDT (N136) & "potential" complex & & & & & $\mathrm{x}$ & & $\mathrm{x}$ & & & & \\
\hline NSS (N141) & "potential" complex & & & & & & & & & $(\mathrm{NG})^{\mathrm{d}}$ & & \\
\hline NCS (N156) & "potential" complex & & & & & & & & & & & \\
\hline NIS (N160) & "potential" complex & & & & & & $\mathrm{x}$ & & & $\mathrm{x}$ & & \\
\hline NDT (N186) & "potential" complex & & & $\mathrm{x}$ & & $x^{e}$ & & & & & & \\
\hline NTS (N197) & "potential" complex & & & & & & & & & & & \\
\hline NKT (N230) & high-mannose & & & & $\mathrm{x}$ & $x^{e}$ & $\mathrm{x}$ & & & $\mathrm{x}$ & $\mathrm{x}$ & $\mathrm{x}$ \\
\hline NGT (N234) & high-mannose & & & $\mathrm{x}$ & $\mathrm{x}$ & $\mathrm{x}$ & & & & & $\mathrm{x}$ & $\mathrm{x}$ \\
\hline NVS (N241) & high-mannose & & & & & & & & & & & \\
\hline NGS (N262) & high-mannose & & & & & & & & & & & \\
\hline NFT (N276) & "potential" complex & & & & & $\mathrm{x}$ & & & & & & \\
\hline NQS (N289) & high-mannose & & & $\mathrm{x}$ & $\mathrm{x}$ & $x^{e}$ & & & & $\mathrm{x}$ & & $\mathrm{x}$ \\
\hline NCT (N295) & high-mannose & $\mathrm{x}$ & $\mathrm{x}$ & $\mathrm{x}$ & & $\mathrm{x}$ & & & $\mathrm{x}$ & $\mathrm{x}$ & $\mathrm{x}$ & \\
\hline NNT (N301) & "potential" complex & & & & $\mathrm{x}$ & $\mathrm{x}$ & & & & & & $\mathrm{x}$ \\
\hline NIS (N332) & high-mannose & & & $\mathrm{x}$ & & & $\mathrm{x}$ & & & & & $\mathrm{x}$ \\
\hline NNT (N339) & high-mannose & & & $\mathrm{x}$ & $\mathrm{x}$ & $\mathrm{x}$ & $\mathrm{x}$ & $\mathrm{x}$ & $\mathrm{x}$ & & & \\
\hline NKT (N356) & "potential" complex & & & & & & & & & & & \\
\hline NST (N386) & high-mannose & & & $\mathrm{x}$ & & $x^{e}$ & & $\mathrm{x}$ & $\mathrm{x}$ & & $\mathrm{x}$ & \\
\hline NST (N392) & high-mannose & & $\mathrm{x}$ & & $\mathrm{x}$ & $x^{e}$ & $\mathrm{x}$ & & $\mathrm{x}$ & $\mathrm{x}$ & & $\mathrm{x}$ \\
\hline NST (N397) ${ }^{b}$ & "potential" complex & & & & & & & & & & & \\
\hline NNT (N406) & "potential" complex & & $\mathrm{x}$ & & & $x^{b}$ & & & & & & $\mathrm{x}$ \\
\hline NIT (N448) & high-mannose & & & & & & $\mathrm{x}$ & & & $\mathrm{x}$ & $\mathrm{x}$ & $\mathrm{x}$ \\
\hline NES $(\mathrm{N} 463)^{\mathrm{c}}$ & "potential" complex & & & & & & & & & & $(\mathrm{NG})^{\mathrm{d}}$ & \\
\hline & Total & 1 & 3 & 8 & 7 & 12 & 6 & 3 & 4 & 6 & 5 & 9 \\
\hline
\end{tabular}

${ }^{\text {a: }}$ Assignment of glycosylation sites according to Leonard et al. [3]; b: The N397 glycan was not present in the wild-type IIIB strain throughout the AH resistance experiments due to the NSTWS sequence deletion as indicated in brackets in Figure 1B. Therefore, the N401 mutation found for the HIV-1 IIIB ${ }^{\text {AHres. }}$ strain corresponds to the N406 according to Leonard et al. [3]; c : N463 is only present in the HIV-1 NL4.3 wild-type strain as N461 and not in the HIV-1 IIIB wild-type strain (1B); ${ }^{\text {d: }}$ (NG): new glycan created; $:$ : x are the $N$-linked glycan deletions used to calculate the fold-resistance for AH in Table 2. 
These $N$-linked glycans are a unique target for the class of carbohydrate-binding agents (CBAs). CBAs can be found in various different species throughout nature such as prokaryotes, algae, plants and vertebrates [12]. They are characterized by a broad array of sugar specificities (such as mannose, glucose, fucose, $\mathrm{N}$-acetylglucosamine or sialic acid). CBAs endowed with antiviral activity target HIV replication via four different pathways (Figure 3): (i) They inhibit entry of free HIV particles in PBMCs, monocyte/macrophages and DCs (Figure 3a); (ii) they block the formation of multinucleated giant cells or syncytia, formed after fusion between persistently HIV-infected T cells and CD4 ${ }^{+}$non-infected T cells (Figure 3b); (iii) they prevent the capture of HIV virions by DC-SIGN (Dendritic Cell-Specific Intercellular adhesion molecule 3 Grabbing Non-integrin) (Figure 3c) and (iv) block subsequent HIV transmission to uninfected $\mathrm{CD}^{+}$target T cells (Figure 3d) [12]. DC-SIGN, expressed on DCs and macrophages, acts as a tetrameric attachment receptor for many sorts of pathogens (e.g., viruses, bacteria, parasites; see reference [10] and references therein for more information). DC-SIGN has specificity for mannose and fucose-containing glycans $[13,14]$, which are, as described above, abundantly present on gp120 of HIV particles. As HIV is able to hijack the endocytic function of DCs, this viral capture is involved in the dissemination of HIV towards the lymph nodes and highlights the ingenious strategies used by HIV for its transfer to infect vulnerable $\mathrm{CD}^{+} \mathrm{T}$ cells [15]. The recent insights that replication competent HIV virions, in contrast to recombinant gp120, contain more oligomannose glycans render the mannose-targeting CBAs as ideal potential candidates for antiviral purposes.

Figure 3. Mechanisms of action of CBAs endowed with anti-HIV acitivity. Four different well-described infection pathways important in HIV pathogenesis, which are all efficiently inhibited by CBAs: (a) HIV-1 infection/replication assay; (b) giant cell or cocultivation assay;

(c) HIV-1 DC-SIGN capture assay and (d) DC-SIGN-related HIV-1 transmission assay.

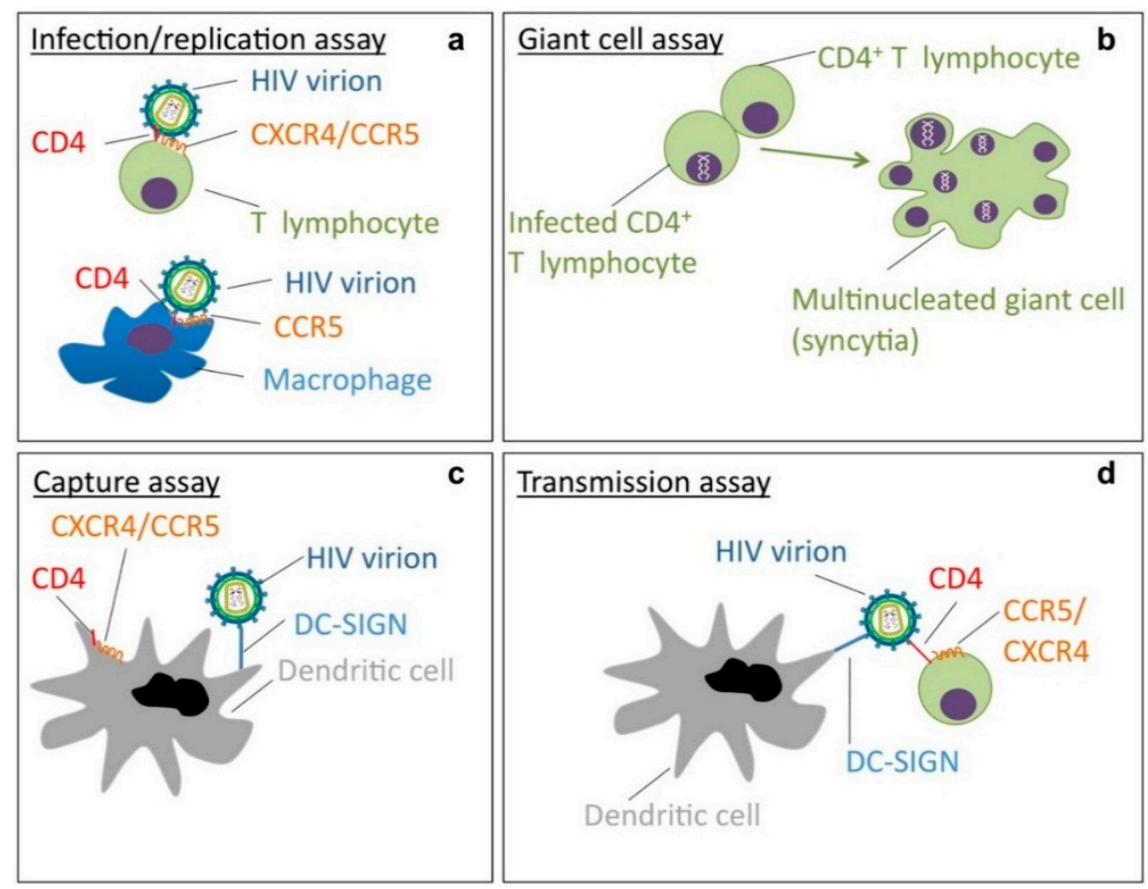

Prolonged exposure of HIV to CBAs can result in the appearance of mutations in the sequon motifs on gp120 that render them resistant to CBAs. This evokes $N$-linked glycan deletions, which creates holes in the protective glycan shield and could trigger cellular and humoral immune responses. In addition, 
those mutations can also affect the viral fitness and infectivity [12]. Here, we will overview and discuss the resistance mutations that appear under the pressure of eleven members of this class of CBAs: $2 \mathrm{G} 12$ $\mathrm{mAb}$, Hippeastrum hybrid agglutinin (HHA), Galanthus nivalis agglutinin (GNA), Actinohivin (AH), Cyanovirin-N (CV-N), Microvirin (MVN), Banana lectin (BanLec), Griffithsin (GRFT), Oscillatoria aghardii agglutinin (OAA), Urtica dioica agglutinin (UDA) and Nicotiana tabacum agglutinin (NICTABA). We also highlight their cross-resistance patterns and their inhibitory effects on $2 \mathrm{G} 12 \mathrm{mAb}$ binding to gp120.

\section{Resistance and Cross-Resistance Pattern of CBAs with Potent Anti-HIV Activity}

\subsection{Mannose-Specific CBAs}

\subsubsection{Monoclonal Antibody 2G12}

In the mid-nineties, the broad-neutralizing $2 \mathrm{G} 12 \mathrm{mAb}$ has been isolated from the blood of an HIV-infected individual [16] and follow-up studies showed a high affinity for man- $\alpha(1,2)$ man-linked sugars of high-mannose type glycans on the silent face of gp120 around the C4/V4 region [17,18], which is actually a poorly immunogenic region [11,19]. Binding inhibition of $2 \mathrm{G} 12 \mathrm{mAb}$ to gp120 was observed in the presence of mannose and not glucose, GlcNAc or galactose [18]. MAb 2G12 has a unique structure as Calarese and coworkers demonstrated, based on crystal structures of Fab 2G12 with unliganded Fab and its complexes with Man ${ }_{9} \mathrm{GlcNAc}_{2}$ or the disaccharide man- $\alpha(1,2)$ man, that the two Fab domains of 2G12 assemble into an interlocked VH domain-swapped dimer [20].

Antiviral activity studies showed that $2 \mathrm{G} 12 \mathrm{mAb}$ broadly neutralized the majority of subtype B viruses (clinical isolates and laboratory strains) and in addition viruses of the non-subtype B group [17,21]. In our lab, we found that $2 \mathrm{G} 12 \mathrm{mAb}$ has rather limited broad-neutralizing activity, as it inhibits only clinical isolates of subtypes A and B and subtype B laboratory strains in the lower $\mu \mathrm{g} / \mathrm{mL}-$ range $(50 \%$ inhibitory concentration or $\left.\mathrm{IC}_{50}: 0.04-1.4 \mu \mathrm{g} / \mathrm{mL}\right)$ [22]. No antiviral activity $\left(\mathrm{IC}_{50}>20 \mu \mathrm{g} / \mathrm{mL}\right)$ was observed against group O HIV-1 strains and HIV-2 [22,23].

Increased $2 \mathrm{G} 12 \mathrm{mAb}$ pressure resulted quickly in HIV-1 resistant strains. Within three weeks (six passages), the HIV-1 NL4.3 ${ }^{2 \mathrm{G} 12 \mathrm{res}}$ virus showed one pure mutation (N295K) at position N295 (Table 1; Figure 2b), resulting in a decreased antiviral activity of $>50$-fold (IC50 $>50 \mu \mathrm{g} / \mathrm{mL}$; Table 2) [22]. In addition, the generated HIV-1 IIIB $^{2 \mathrm{G} 12 \mathrm{res}}$ strain developed three mutations in gp120 at N-glycosylation motifs: T297T/I (N295), T394T/I (N392) and T408T/I (N406) (Table 1; Figure 2c). These mutations resulted also in a complete loss of antiviral activity $\left(\mathrm{IC}_{50}>50 \mu \mathrm{g} / \mathrm{mL}\right.$ ) (Table 2) [22]. These findings are in agreement with previously published epitope mapping studies. Alanine scan mutagenesis experiments showed a significant decreased $2 \mathrm{G} 12 \mathrm{mAb}$ binding to gp120 after elimination of the asparagines at position N295, N332, N339, N386 and N392. More in depth studies indicated that N295, N332 and N392 are crucial for interaction with gp120 and withdrawal of the N339 and N386 glycosylations will produce more conformational perturbations or protein misfolding, indicating them as less critical for antibody binding [18,24]. Many clade C HIV-1 strains are resistant to 2G12 mAb neutralization [22,25], however introduction of N295 glycosylation site restored mAb binding [25]. 
Table 2. Resistance and cross-resistance profile of CBAs of in vitro generated CBA-resistant HIV-1 strains.

\begin{tabular}{|c|c|c|c|c|c|c|c|c|c|c|c|}
\hline CBAs & $\mathrm{NL}_{4.3^{2 \mathrm{G} 12 \mathrm{res}}}$ & IIIB $^{2 \mathrm{G} 12 \mathrm{res}}$ & IIIB ${ }^{\text {HHAres }}$ & IIIB $^{\text {GNAres }}$ & IIIB ${ }^{\text {AHres }}$ & IIIB $^{\text {CV-Nres }}$ & $\mathrm{NL}_{4.3^{\mathrm{CV}-\mathrm{Nres}}}$ & NL4.3 $^{\text {MVNres }}$ & IIIB $^{\text {BanLecres }}$ & IIIB $^{\text {GRFTres }}$ & IIIB $^{\text {UDAres }}$ \\
\hline $\mathrm{AH}$ & N.D. ${ }^{a}$ & N.D. & N.D. & N.D. & $19^{b}$ & N.D. & N.D. & N.D. & $>66$ & 118 & N.D. \\
\hline MVN & 2 & N.D. & N.D. & N.D. & N.D. & N.D. & N.D. & $>100$ & N.D. & 4 & N.D. \\
\hline $2 \mathrm{G} 12 \mathrm{mAb}$ & $>50$ & $>36$ & $>15$ & $>15$ & $>25$ & $>45$ & $>45$ & $>38$ & $>25$ & $>35$ & $>29$ \\
\hline НHA & 12 & 2 & 919 & 490 & 1 & 17 & 4 & 3 & 3 & 5 & 117 \\
\hline GNA & 6 & 1 & 926 & 581 & N.D. & 23 & 1 & 2 & N.D. & N.D. & 39 \\
\hline BanLec & 1 & N.D. & N.D. & N.D. & N.D. & N.D. & N.D. & 5 & 24 & 13 & N.D. \\
\hline GRFT & 10 & N.D. & N.D. & N.D. & N.D. & N.D. & N.D. & 14 & $>106$ & $>1900$ & N.D. \\
\hline $\mathrm{CV}-\mathrm{N}$ & 1 & 3 & 29 & 11 & N.D. & 20 & 7 & 4 & N.D. & N.D. & 83 \\
\hline OAA & 3 & N.D. & N.D. & N.D. & N.D. & N.D. & N.D. & 2 & 2 & 2 & N.D. \\
\hline UDA & 8 & N.D. & N.D. & N.D. & 1 & 1 & 3 & 3 & 1 & 3 & 24 \\
\hline
\end{tabular}

Notes: ${ }^{a}:$ N.D. Not determined; ${ }^{b}$ : Legend fold resistance: the indicated colors describe the antiviral activity [more- (shown in blue) or less active (shown in green-yellow-orange and red)] of various CBAs against different in vitro generated CBA-resistant HIV-1 strains.

\begin{tabular}{|c|}
\hline Increased sensitivity \\
\hline 1 (none) \\
\hline$\geq 2-9$ (low) \\
\hline$\geq 10-24$ (moderate) \\
\hline$\geq 25-49$ (high) \\
\hline$\geq 50$ (very high) \\
\hline
\end{tabular}


The HIV-1 NL4.3 $3^{\text {G12res }}$ isolate showed an increased (three to 12-fold) susceptibility to the CBAs OAA, HHA, GNA and UDA (Table 2) [22,26,27]. CV-N and BanLec fully kept their inhibitory activity [23]. This 2G12-resistant virus demonstrated low to moderate levels of cross-resistance with, respectively, MVN (2-fold) and GRFT (10-fold) [23,26]. Remarkably, only the NL4.3 ${ }^{2 \mathrm{G} 12 \mathrm{res}}$ HIV-1 strain showed increased sensitivity to certain CBAs. Such observations were not made using the IIIB ${ }^{\text {G12res }}$ HIV-1 isolate (Table 2; Figure 2b,c), which could indicate cell line- and/or viral-dependent effects or an ideal structural conformation for certain CBAs when only N295 was deleted on gp120 [22].

\subsubsection{Hippeastrum Hybrid Agglutinin (HHA)}

HHA was isolated from the bulbs of Amaryllis and exists as a tetrameric protein. It has a total molecular weight of $50 \mathrm{kDa}$ and showed high specificity for $\alpha(1,3)$ and $\alpha(1,6)$-mannoses [28]. HHA demonstrated a very potent antiretroviral activity in replication and transmission assays against HIV-1 and HIV-2 in various cell lines (e.g., CEM cells, MT-4, PBMCs and macrophages) with IC50s ranging from 1.8 to $980 \mathrm{nM}[22,23,26,29-35]$.

Our laboratory generated a HIV-1 IIIB $^{\text {HHAres }}$ strain in CEM cell cultures. Up to 90 subcultivations were required to replicate in the presence of $500 \mu \mathrm{g} / \mathrm{mL}$ HHA. Prolonged HHA exposure resulted in the loss of eight $N$-linked glycans in gp120 due to the following mutations: T90I (N88), T188N (N186), T236A (N234), N289K (N289), T297I (N295), S334N (N332), T341I (N339) and N386D (N386) (Table 1; Figure 2d). This led to a $>900$-fold increase in IC50-values from $4.2 \pm 2.4 \mathrm{nM}$ (wild-type IIIB strain) to $3.9 \pm 1.9 \mu \mathrm{M}$ (HIV-1 IIIB ${ }^{\mathrm{HHAres}}$ strain) (Table 2) [35]. Unfortunately, the HHA-resistant variant was found to be approximately 10-fold more infectious than the wild-type virus in CEM cells; the cell line in which the resistant virus was generated [35]. A similar degree of increased infectivity was also observed in the HIV-1 susceptible astroglioma transfected cell line U87.CD4.CXCR4 [35]. Moreover, this HIV-1 HHA-resistant IIIB strain showed moderate to very high levels of resistance against GNA (>900-fold), 2G12 mAb (>15-fold) and CV-N (29-fold). MAb 2G12 lost once more its activity completely ( $\left.\mathrm{IC}_{50}>25 \mu \mathrm{g} / \mathrm{mL}\right)$ [35].

\subsubsection{Galanthus Nivalis Agglutinin (GNA)}

GNA was isolated from the bulbs of Galanthus nivalis (snowdrop). It exists, like HHA, as a tetrameric protein with a molecular weight of $50 \mathrm{kDa}$ and has specificity for $\alpha(1,3)$ mannoses [36]. GNA has a broad-spectrum antiretroviral activity in replication and cell-to-cell transmission assays (IC50: 1.7-540 nM) [22,23,26,30-35]. No to weak anti-HIV activity was observed against HIV-1 subtype C strain ETH2220 and subtype G strain BCF-DIOUM with $\mathrm{IC}_{50 \mathrm{~S}} \geq 2 \mu \mathrm{M}[22,35]$.

The HIV-1 IIIB ${ }^{\text {GNAres }}$ strain was also selected in CEM T cells [35]. It took up to 70 passages to generate a resistant isolate that could replicate in the presence of $500 \mu \mathrm{g} / \mathrm{mL}$ of GNA. Mutation analysis of gp120 revealed that seven $N$-linked glycosylation sites were affected under GNA pressure: T90T/I (N88); T232M (N230); N234K (N234); N289N/D and/or S291S/F (N289); N301Y (N301); T341I (N339) and T394I (N392) (Table 1 and Figure 2(e)). This resulted in a $>500$-fold drug resistance profile as the $\mathrm{IC}_{50}$ increased from $5.4 \pm 1.2 \mathrm{nM}$ (wild-type IIIB) to $3.1 \pm 2 \mu \mathrm{M}$ (HIV-1 IIIB ${ }^{\text {GNAres }}$ isolate). The resistant strain demonstrated also an increased viral fitness (approximately 30-fold) compared to wild-type IIIB in CEM and U87.CD4.CXCR4 cell cultures [35]. 
The GNA-resistant isolate proved to be highly resistant to HHA (490-fold) and moderate to CV-N (11-fold). MAb 2 G12 became completely inactive $\left(\mathrm{IC}_{50}>25 \mu \mathrm{g} / \mathrm{mL}\right)$ and demonstrated a resistance profile of $>15$-fold (Table 2) [35].

\subsubsection{Actinohivin $(\mathrm{AH})$}

$\mathrm{AH}(12.5 \mathrm{kDa})$ has been isolated from the actinomycete Longispora albida $\mathrm{K} 97-0003^{\mathrm{T}}$ [37]. AH contains 114 amino acids and consists of three segments, each containing one sugar-binding pocket, as observed by 3D analysis [38]. It exhibits a strong and highly specific affinity for gp 120 and demonstrates very potent anti-HIV activity in replication and cocultivation assays in the lower nM-range with $\mathrm{IC}_{50} \mathrm{~s}$ varying from 25 to $1200 \mathrm{nM}$ [29,37]. However, its anti-HIV activity can be greatly improved through dimerization [39]. Various studies demonstrated that AH has specificity for man- $\alpha(1,2)$ man structures and pointed which amino acids are essential for its anti-HIV activity [29,40]. The binding of AH to gp120 can be inhibited by yeast mannan [41] and only by $[\alpha(1,2) \mathrm{man}]_{3}$ oligosaccharides, indicating no affinity for $\alpha 1,3 / \alpha 1,6$-mannose or GlcNAc-based sugars [29].

Exposure of the HIV-1 strain IIIB in CEM cell cultures to increasing concentrations of AH, resulted in the loss of up to 12 different $N$-linked glycans (Table 1) [29]. The following resistance mutations were found in the sequons of various sequenced resistant HIV-1 isolates: T138T/I (N136); T188N/T (N186); T232T/M, T232K/T, T232K and T232M (N230); N234K/N (N234); N276N/I (N276); N289N/S, N289N/Y, N289Y, S291S/F, S291V/F, S291F (N289); T297T/I, T297T/A, T297A (N295); T303T/I (N301); N339K/N, N339N/D (N339); N386K/N (N386); T394T/I, T394I (N392); T403T/I (N401) (Figure 2(f)). Surprisingly, a $N$-linked glycosylation was also created at position 29 [29]. The highest degree of $\mathrm{AH}$ resistance (19-fold) was observed with the following five mutations appearing simultaneously in gp120: T188N/T (N186), T232K/T (N230), N289N/Y (N289), N386K/N (N386) and T394T/I (N392), as its antiviral activity decreased from $25 \pm 5 \mathrm{nM}$ (wild-type HIV-1 IIIB) to $480 \pm 89 \mathrm{nM}$ (HIV-1 IIIB ${ }^{\text {AHres }}$ strain) (Tables 1 and 2) [29].

Cross-resistance studies demonstrated that the wild-type IIIB and generated HIV-1 IIIB ${ }^{\text {AHres }}$ strain were equally susceptible to the plant lectins HHA and UDA, while $2 \mathrm{G} 12 \mathrm{mAb}$ lost $>25$-fold of its activity (Table 2), and was thus considered inactive [29].

\subsubsection{Cyanovirin-N (CV-N)}

$\mathrm{CV}-\mathrm{N}$ is an $11 \mathrm{kDa}$ protein isolated from the blue-green algae Nostoc ellipsosporum [42]. It consists of 101 amino acids and structure analysis indicated that CV-N exists a monomer [43]. However, Yang et al. reported crystal structures that contain domain swapped CV-N dimers [44]. Later studies demonstrated that CV-N can exist in solution in both monomeric and dimeric form [45]. Four sugar-binding domains can be found in the dimeric form. Various studies pointed out that CV-N has a high affinity for high-mannose glycans with eight or nine mannose residues and that it recognizes the man $\alpha(1,2)$-man moieties [46-48].

CV-N demonstrated a very potent and consistent anti-HIV-1 and anti-HIV-2 activity against $\mathrm{T}$ cell line adapted strains and clinical isolates in cell cultures with $\mathrm{IC}_{50}$ s varying between 0.1 and 164 nM [22,26,34,42,49,50]. 
CV-N resistance studies were performed using HIV-1 strains IIIB and NL4.3 with gradually increasing concentrations of CV-N ranging from $0.1 \mu \mathrm{g} / \mathrm{mL}(\sim 9 \mathrm{nM})$ to $2 \mu \mathrm{g} / \mathrm{mL}(\sim 180 \mathrm{nM})$, due to cytotoxicity problems at concentrations $>2 \mu \mathrm{g} / \mathrm{mL}$ in CEM cell cultures the dosage could not be further increased. A total of seven virus isolates were then sequenced for $N$-linked glycan deletions [49]. Here, we will focus on mutant strains showing the highest levels of resistance to CV-N. Six N-glycosylation sites were found to be deleted in HIV-1 $\mathrm{IIIB}^{\mathrm{CV}-\mathrm{Nres}}$ virus based on the following observed mutations: S162S/N (N160); T232T/M (N230); S334N (N332); N339S (N339); N392N/T (N392) and N448S (N448). Two mutations were observed in HIV-1 NL4.3 $3^{\mathrm{CV}-\mathrm{Nres}}$ isolate: T341A (N339) and N386D (N386). One isolate in the NL4.3 resistant arm showed a mutation at position N136 (N136N/K), which intriguingly disappeared at higher concentrations. Overall, these data indicate that up to eight $N$-linked glycans can be deleted in the presence of increasing concentrations of CV-N (Table 1, Figure $2 \mathrm{~g}-\mathrm{h}$ ). A 20 -fold resistance ratio was observed for CV-N in the IIIB selection arm, as the $\mathrm{IC}_{50}$ increased from $2 \pm 1 \mathrm{nM}$ (wild-type IIIB) to $40 \pm 21 \mathrm{nM}$ (IIIB ${ }^{\mathrm{CV}-\mathrm{Nres}}$ strain) [49]. These data indicated that the combined deletion of N230, N392 and N448 resulted in a high level of CV-N resistance [49]. The NL4.3 ${ }^{\mathrm{CV}-\mathrm{Nres}}$ isolate evoked only a 7-fold decrease in antiviral activity ( $\mathrm{IC}_{50}: 0.7 \pm 0.5 \mathrm{nM}$ [wild-type]; $5 \pm 0 \mathrm{nM}$ [CV-N-resistant strain]) [49]. Around the same period, a comparable study by $\mathrm{Hu}$ et al. in C8166 cells using HIV-1 IIIB, resulted in a CV-N-strain with five glycans of the high-mannose type removed at positions N289, N332, N339, N392 and N448, resulting in a 24-fold increase of IC50-values [51]. Four of the abovementioned sequon mutations were also described in our laboratory [49], however Hu and coworkers did not observe the mutation at position N230 and according to their mutagenesis study the loss of N230 did not affect the antiviral activity of CV-N [51].

As shown in Table 2, 2G12 mAb completely lost its antiviral activity ( $\mathrm{CC}_{50}>50 \mu \mathrm{g} / \mathrm{mL}$; $>45$-fold) against both generated CV-N-resistant strains, while the GlcNAc-specific lectin UDA lost no more than a 3-fold of its inhibitory activity. The HIV-1 IIIB $^{\mathrm{CV}-\mathrm{Nres}}$ strain was, respectively, 17-fold and 23-fold less susceptible to the plant lectins HHA and GNA [49]. The CV-N-resistant isolate from Hu and colleagues, showed cross-resistance against GNA (21-fold) and GRFT (20-fold). MAb 2G12 lost completely its antiviral activity $\left(\mathrm{IC}_{50}>40 \mu \mathrm{g} / \mathrm{mL}\right.$ ) [51]. Minor differences in cross-resistance were seen with the NL4.3-resistant CV-N variant (Table 2), which can be explained by the different sugar deletions throughout gp120.

\subsubsection{Microvirin (MVN)}

MVN (14.3 kDa) was isolated from the cyanobacterium Microcystis aeruginosa PCC7806 and shows $33 \%$ identity with cyanovirin-N (CV-N) [52]. MVN consists of 108 amino acids and has a monomeric form in solution. Only one carbohydrate-recognition site is present, which shows specificity for man- $\alpha(1,2)$ man moieties [52,53]. MVN demonstrated a broad-spectrum anti-HIV-1 activity in PBMC cultures (IC50s: 2.1-167 nM) with no cytotoxicity. Comparable activity was also observed in giant cell formation- and DC-SIGN-mediated transmission assays (IC50s: $125 \mathrm{nM}-189 \mathrm{nM}$ ) [26].

MVN resistance studies using HIV-1 NL4.3 in MT-4 cells resulted in four mutations in N-linked glycosylation motifs of gp120 at positions: T297I (N295); T341T/I (N339); N386K/N (N386) and N392D (N392) (Table 1 and Figure 2i) [26]. According to these deletions, the $\mathrm{IC}_{50}$ of $\mathrm{MVN}$ increased $>100$-fold from $5.6 \pm 1.4 \mathrm{nM}$ (wild-type HIV-1 NL4.3) to $576 \pm 84 \mathrm{nM}$ (HIV-1 NL4.3 ${ }^{\text {MVNres }}$ virus) (Table 2). 
The MVN-resistant isolate showed a three to 4-fold degree of resistance against CV-N, HHA and UDA. No antiviral activity could be observed for MAb 2G12 (IC $50>50 \mu \mathrm{g} / \mathrm{mL} ;>38$-fold resistance). In contrast, the isolate became a 2-fold more susceptible for the plant lectin GNA (Table 2) [26]. Later studies showed that this resistant virus, compared to the wild-type NL4.3 strain, was also two to 5-fold more susceptible to other CBAs such as OAA and BanLec, In addition, the MVN-resistant strain showed a 14-fold decreased susceptibility to GRFT (Table 2) [23,27].

\subsubsection{Banana Lectin (BanLec)}

BanLec can be purified from the Musa paradisiac or Musa acuminata or in the leaves of intact plants after jasmonate treatment $[54,55]$. BanLec exists as a homodimeric protein with two subunits of $15 \mathrm{kDa}$. Cloning studies showed that it belongs to the group of mannose-specific jacalin-related lectins, and was found to be a $\mathrm{T}$ cell mitogen $[54,55]$. Each monomer has two carbohydrate-binding sites, of which the second was quite unique in the jacalin-related lectin family [56]. Sugar binding experiments indicated its specificity for high-mannose type glycans containing eight or nine mannose residues and no binding with Man6 or mono- and bi-antennary complex type glycans [54]. Later binding and crystal structure studies showed unique carbohydrate-binding properties to internal 3-O- $\alpha$-D-glucopyranosyl units and $\alpha(1,3)$-linked glucosyl residues as well as $\beta(1,3)$-linkages at the reducing termini [56-58].

Various in vitro replication and transmission assays demonstrated that BanLec has a very potent and consistent anti-HIV-1 and anti-HIV-2 activity (IC50: 0.13-9.7 $\mathrm{nM}$ ) [23,30,59,60]. The antiviral activity of BanLec was more pronounced than its weak mitogenic activity observed in PBMC cultures [23].

In our lab, we generated a HIV-1 IIIB $^{\text {BanLecres }}$ strain in C8166 cells. After 59 passages, six mutations were found in gp120: N160N/D (N160); N230N/T and T232T/M (N230); S291F (N289); T297I (N295); N392K (N392) and N448K/N (N448) (Table 1 and Figure 2j). At position 142 the serine to asparagine mutation (S142N/S) results in a new glycan, neighboring the existing N141 "potential" complex glycan (Figure 1B and Table 1) (unpublished data). Its function is not known, but it could be a compensatory glycan important for viral fitness. The resistance profile of this mutant virus against BanLec and various other CBAs was evaluated in MT-4 cells, TZM-bl cells and PBMCs. Pooled resistance data showed a 24-fold degree of resistance to BanLec (Table 2). Very high levels of cross-resistance of this generated BanLec-resistant virus were observed against the CBAs AH and GRFT ( $>66$-fold). No antiviral activity was observed with MAb 2G12 ( $\mathrm{IC}_{50}>20 \mu \mathrm{g} / \mathrm{mL}$ ), while HHA and OAA remained active albeit to a lesser degree (two to 3-fold) (Table 2). No shift in susceptibility was observed for this resistant isolate to the GlcNAc-binding CBA UDA.

\subsubsection{Griffithsin (GRFT)}

GRFT was originally isolated from the red algae Griffithsia sp. in the waters of New Zealand and exists as a domain swapped unique dimeric protein. Each monomer, which has a molecular weight of $12.7 \mathrm{kDa}$, consists of 121 amino acids and has three very similar carbohydrate-binding pockets [61,62]. Sugar-binding studies showed that the binding of GRFT to soluble gp120 was inhibited by glucose, mannose and GlcNAc [61]. Various crystal structures and modeling studies demonstrated an interaction of GRFT with high-type mannose (Man, GlcNAc$_{2}$ ), mannose, GlcNAc, $(1,6) \alpha$-mannobiose, glucose and maltose [62-64]. Monomeric forms of GRFT exhibited a strong reduction in its anti-HIV activity $[65,66]$, 
which indicates that the anti-HIV activity of GRFT stems from cross-linking and aggregation of virions through multivalent interactions with the carbohydrates present on gp120.

It is the most potent anti-HIV CBA described to date with a consistent and broad-spectrum antiviral activity even in the $\mathrm{pM}$ to lower nM-range (IC50: $2 \mathrm{pM}-56 \mathrm{nM}$ ) in infection/replication assays and different cell-to-cell transmission systems [23,60,61,67-71].

Resistance selection experiments resulted in five high-mannose $N$-linked glycan deletions in gp120 of HIV-1 IIIB ${ }^{\text {GRFTres }}$ strain developed in C8166 cell cultures: T232M (N230), T236I (N234), N295Y (N295), N386N/D and T388T/A (N386) and T450N (N448) (Table 1 and Figure 2k) [27]. A >1900-fold decrease in susceptibility for GRFT was observed with this mutant virus in MT-4 cells [IC50: $20.5 \pm 3.8 \mathrm{pM}$ (wild-type IIIB) to $>39 \mathrm{nM}$ (GRFT-resistant strain)]. The observed mutations are in accordance with the findings of other research groups, who indicated also the importance of N234, N295 and N448 for GRFT-resistance [68,69]. Moreover, long-term exposure of GRFT in our cell culture system induced a novel sequon at position N463 created by the proline to serine substitution at position 465 (P465S) (Table 1). The importance of this new glycan is not known, however, it should be noticed that this $N$-linked glycan is present in the original HIV-1 IIIB strain, according to Leonard and coworkers [3] and in the HIV-1 NL4.3 wild-type strain (Figure 1B). These data also highlight that the antiviral potency of CBAs does not impact the emergence of the number of mutations. The GRFT-mutant virus exhibited five mutations, while AH or HHA-resistant isolates obtained between eight and 12 mutations, all of them resulting in $\mathrm{N}$-linked glycan deletions (Table 1 ). These observations indicate that the interaction kinetics with gp120 (and perhaps gp41) and the multivalent interactions with the $N$-linked glycans are the most important factors involved in viral resistance.

As indicated in Table 2, antiviral studies using the HIV-1 IIIB ${ }^{\text {GRFTres }}$ strain in MT-4- and TZM-bl cells demonstrated high levels of cross-resistance against AH (118-fold). This GRFT-resistant strain showed also low to moderate resistance against MVN (4-fold), UDA (3-fold), OAA (2-fold) and BanLec (13-fold). The anti-carbohydrate-binding mAb 2G12 demonstrated no antiviral activity ( $\mathrm{IC}_{50}>25 \mu \mathrm{g} / \mathrm{mL}$ ) ([27] and unpublished data). Huang et al. mentioned that removal of N295 and N448 on gp120 renders HIV-1 highly resistant to GRFT, but maintained its sensitivity to CV-N and GNA [68]. Our GRFT-resistant isolate became 5-fold more sensitive to HHA. A comparable trend towards HHA was also observed using the NL4.3 ${ }^{2 \mathrm{G} 12 \mathrm{res}} \mathrm{HIV}-1$ strain (Table 2).

\subsubsection{Oscillatoria Agardhii Agglutinin (OAA)}

OAA was isolated from the cyanobacterium Oscillatoria agardhii strain NIES-204 [72,73]. It has a molecular weight of $13.9 \mathrm{kDa}$ and recognizes, as opposed to all other CBAs, the $\alpha 3, \alpha 6$-mannopentaose core of Man8/9 [74]. Recently, we could demonstrate that OAA has very consistent broad-spectrum anti-HIV activity in the lower nM-range ( $\mathrm{IC}_{50}$ : $19-60 \mathrm{nM}$ ) in several replication and transmission assays [27].

As OAA targets the branched central core unit of Man8/9, the HIV-1 strains resistant against MVN, BanLec and GRFT only displayed a 2-fold decrease in susceptibility for OAA (Table 2). As observed previously for the plant lectins HHA and GNA, the HIV-1 NL4.3 ${ }^{2 \mathrm{G} 12 \text { res. }}$ isolate was found to be more susceptible for OAA (Table 2) [27]. Unfortunately, due to a low selectivity index (SI) in our cell culture system (SI 13), we were not able to generate an NL4.3 $3^{\text {OAAres }}$ HIV-1 strain (unpublished data). 


\subsection{N-Acetylglucosamine (GlcNAc)-Specific CBAs}

\subsubsection{Urtica Dioica Agglutinin (UDA)}

Urtica dioica agglutinin (UDA) is a monomeric GlcNAc-specific protein derived from the stinging nettle rhizomes. It has a total molecular weight of $8.5 \mathrm{kDa}$ and contains two carbohydrate-binding sites with different affinities [75,76]. Structural modeling indicated that UDA efficiently interacts with the GlcNAc $_{2} \mathrm{Man}_{1}$ residue, which is part of the core unit (Figure 1A) of glycans on gp120 [34].

UDA demonstrated a potent broad-spectrum anti-HIV-1 and anti-HIV-2 activity against T cell line adapted strains and clinical isolates in different cell lines (e.g., MT-4, CEM, PBMCs and macrophages) with $\mathrm{IC}_{50}$ s ranging from 0.052 to $2.8 \mu \mathrm{M}[30,31,34,77]$.

HIV-1 IIIB ${ }^{\text {UDAres }}$ virus was generated in CEM cell cultures, which took more than nine months ( $>90$ passages) before the virus was able to replicate in the presence of $200 \mu \mathrm{g} / \mathrm{mL}$ of UDA [34]. Resistance mutations analysis showed that nine pure mutations occurred at $N$-linked glycosylation sites: T90I (N88), N230D (N230), T236I (N234), N289T (N289), N301Y (N301), S334N (N332), T394I (N392), N406Y (N406) and N448D (N448) (Table 1; Figure 2(1)). These deletions made the virus resistant as the $\mathrm{IC}_{50}$ shifts from $0.14 \pm 0.04 \mu \mathrm{M}$ (wild-type IIIB) to $3.3 \pm 0.05 \mu \mathrm{M}$ (UDA-resistant strain) (Table 2). The viral fitness of this resistant strain showed no marked differences with wild-type HIV-1 IIIB in CEM cells [34].

The mutant HIV-1 strain was highly resistant against HHA (117-fold) and CV-N (83-fold). The antiviral acitivity of GNA was a 39-fold reduced, while $2 \mathrm{G} 12 \mathrm{mAb}$ demonstrated no activity at all $\left(\mathrm{IC}_{50}>50 \mu \mathrm{g} / \mathrm{mL}\right.$ ) (Table 2) [34]. In addition, novel surface plasmon resonance (SPR) data showed that UDA binding to recombinant gp120 is also inhibited in the presence of certain mannoses, which demonstrates the broader sugar specificity of UDA than solely GlcNAc [78].

\subsubsection{Nicotiana Tabacum Agglutinin (NICTABA)}

NICTABA is a non-glycosylated homodimeric protein of $38 \mathrm{kDa}$, which is expressed in the leaves of the tobacco plant after treatment with jasmonates $[79,80]$. It resides as a nucleocytoplasmatic plant lectin, where it is believed to be a signaling protein during stress physiology [81]. Glycan binding studies demonstrated that NICTABA has specificity for GlcNAc-oligomers on high-mannose and complex $N$-glycans [79,82]. Additional experiments using SPR technology indicate that NICTABA is a highly-specific GlcNAc binding lectin [78].

NICTABA has a very consistent anti-HIV activity in the lower nM-range (IC50: 5-230 nM) in different cell lines $[30,78]$ and unfortunately, due to low selectivity indices (SI $\sim 21$ ) in cell cultures, we were not able to generate an HIV-1 ${ }^{\text {Nicatabares }}$ strain (unpublished data). No cross-resistance data are available for NICTABA on CBA-resistant HIV-1 strains so far.

\section{Inhibition of $2 \mathrm{G} 12 \mathrm{mAb}$ Binding to gp120 by CBAs}

As mentioned above, Scanlan and coworkers demonstrated that the high mannose-type glycans N295, N332, N339, N386 and N392 are important for optimal 2G12 mAb binding [18]. Regarding Tables 1 and 2 , it seems quite obvious that the anti-carbohydrate binding $\mathrm{mAb} 2 \mathrm{G} 12$ possessed no longer antiviral 
activity against the generated CBA-resistant HIV-1 strains. Since for each of these strains, at least one of the mentioned high-mannose type $N$-linked glycans by Scanlan et al. [18], was deleted under selective prolonged CBA pressure.

In addition, Scanlan and coworkers also highlighted that CV-N was able to inhibit the binding of $2 \mathrm{G} 12 \mathrm{mAb}$ to gp120, but not vice versa [18]. Our data using MT-4/NL4.3 cells, correspond with these findings (Table 3 ).

Table 3. CBAs inhibiting $2 \mathrm{G} 12 \mathrm{mAb}$ binding to gp120 expressed on HIV-1 NL4.3 infected T cells.

\begin{tabular}{|c|c|c|c|}
\hline CBA & Binding Inhibition & $\mathrm{IC}_{50}(\mathrm{nM})$ & References \\
\hline HHA $^{a}$ & Yes & $28-39$ & [22]/unpublished data \\
\hline GNA $^{a}$ & Yes & $23-76$ & {$[22]$} \\
\hline $\mathrm{AH}$ & Yes & 93 & [29] \\
\hline $\mathrm{CV}-\mathrm{N}^{\mathrm{a}}$ & Yes & $16-28$ & {$[22,26]$} \\
\hline MVN & Yes & 259 & {$[26]$} \\
\hline BanLec $^{b}$ & Yes & $4.5-14$ & [59]/unpublished data \\
\hline GRFT $^{b}$ & Yes & 0.57 & [61]/unpublished data \\
\hline OAA & Yes & 21 & {$[27]$} \\
\hline UDA & Yes & 1000 & [78] \\
\hline NICTABA & No & $>1000$ & [78] \\
\hline
\end{tabular}

a: data also obtained against HIV-1 strains IIIB, MN and NDK. b: data from [59] and [61] were obtained against rgp120.

As further shown in Table 3, all of the investigated CBAs, with exception of NICTABA, inhibited dose-dependently the binding of $2 \mathrm{G} 12 \mathrm{mAb}$ to gp120 on NL4.3 infected MT-4 cells. The best $2 \mathrm{G} 12$ mAb binding inhibitors to gp120 were the mannose-specific lectins GRFT and BanLec with $\mathrm{IC}_{50 \mathrm{~S}}$ varying between 0.75 and $14 \mathrm{nM}$. These inhibitory data are in accordance with previously published observations of several binding studies [59,61]. The GlcNAc-binding CBA UDA demonstrated the weakest inhibitory profile ( $\mathrm{IC}_{50}: 1000 \mathrm{nM}$ ) (Table 3). In most cases, these differences in $2 \mathrm{G} 12 \mathrm{mAb}$ inhibitory binding potential correlated with their anti-HIV activity. As mentioned above, NICTABA is the only CBA that does not block the binding of $2 \mathrm{G} 12 \mathrm{mAb}$ to recombinant gp120 (IC $50>40 \mu \mathrm{g} / \mathrm{mL}$ or $>1000 \mathrm{nM}$ ) (Table 3) [78]. Surprisingly, we could demonstrate that OAA also inhibited dose-dependently the binding of 2G12 mAb to gp120 (Table 3), which was quite unique, regarding the sugar specificity of this lectin. Overall, these data demonstrate that the majority of the anti-HIV CBAs target the 2G12 $\mathrm{mAb}$ epitope directly or alter the conformational epitope structure.

\section{CBAs: A Role in HIV Prevention or Treatment?}

By targeting viral transmission and entry/infection in four different pathways (Figure 3), as well as their high genetic barrier to resistance, the CBAs can be seen as a very promising class of agents in microbicidal applications (e.g., vaginal/rectal gels, creams, intravaginal ring systems) to prevent HIV infection in women and men [12].

The Centre for the AIDS Programme of Reseach in South-Africa (CAPRISA) 004 trial was the first breakthrough in the field of microbicidal research, which showed for the first time that HIV prevention 
was possible with a vaginal $1 \%$ tenofovir gel with two applications of treatment every $24 \mathrm{~h}$ [83]. However, as is done for HIV treatment, the prevention (or pre-exposure prophylaxis) strategy will also presumably comprise at least two antiretroviral agents. We could demonstrate that tenofovir (and other potent antiretroviral agents) showed synergistic to additive effects in different cell lines with various CBAs on viral transmission and on infection/replication of HIV strains having different envelope glycosylation patterns $[30,60,70]$. Remarkably, paired CBA combinations mainly showed synergistic activity against wild-type X4 and R5 HIV-1 strains $[23,53]$. The most surprising results were observed using HHA and GNA, which showed rather antagonistic to low additive effects on wild-type HIV-1 replication, but potent synergy against the $2 \mathrm{G} 12 \mathrm{mAb}$-resistant and MVN-resistant HIV-1 strains. These data suggest that certain deleted $N$-linked glycans in the mutant gp120 proteins (Figures 1 and 2) create holes and/or conformational changes on the surface, which result in better binding pockets for certain CBAs (such as HHA and GNA) to allow synergy. Such findings were in accordance with previously published data on increased activity of single CBA treatment on 2G12 mAb- and MVN-resistant strains (Table 2) [22,26]. It was also suggested that glycan deletions could render gp120 more susceptible to neutralizing antibodies [12]. Experiments with immunoglobulins and sera derived from HIV $-1^{+}$individuals showed that mutant viral envelopes were more sensitive than the wild-type [51]. Rhesus monkeys infected with mutant forms of simian immunodeficiency virus (SIV), having lost two glycosylation sites, produced more neutralizing antibodies, than the animals infected with parental virus [84].

A degree of synergy on antiviral activity with paired CBA combinations in HIV-1 replication assays, was also observed when the 2G12 mAb/HHA combination was evaluated in HIV-1 NL4.3 resistance experiments using C8166 T lymphoma cells. This CBA combination strategy markedly delayed drug resistance development and compromised viral fitness [85]. The anti-carbohydrate binding mAb $2 \mathrm{G} 12$ recognizes a specific epitope on gp120, which resulted very quickly in virus breakthrough [22]. Fast drug resistance development ( $\leq 5$ passages) was likewise observed with members of the class of reverse transcriptase inhibitors (RTIs) (e.g., lamivudine) (data not shown). This process can be avoided by combining different antiretroviral agents, as used in highly active antiretroviral therapy (HAART). Other CBAs (e.g., HHA, GNA or GRFT) have multivalent interactions with the glycans on gp120 and create cross-links. Interesting observations described in this review were the inactivity of the $2 \mathrm{G} 12 \mathrm{mAb}$ against all evaluated CBA-resistant isolates (Table 2) and in addition all CBAs, with exception of NICTABA, interfered directly or indirectly with the $2 \mathrm{G} 12 \mathrm{mAb}$ binding epitope (Table 3 ).

A closer look at the mutations in the in vitro generated NL4. $3^{\text {HHAres }}$ HIV-1 strain showed N-linked glycan deletions at two "potential" complex glycan sites (N160 and N463) and at four high-mannose sites (N230, N289; N339 and N386). The mutation in the sequon at N160 resulted in a new sequon at N162. Three of these mutations were also observed previously using CEM cells and HIV-1 strain IIIB: N289, N339 and N386, which were all high-type mannoses (Table 1) $[35,85]$. The NL4.3 ${ }^{2 \mathrm{G} 12 \mathrm{res}} \mathrm{HIV}-1$ strain had only one glycan deletion at position N392 [85]. This mutation again corresponds with previously published results with respect to $2 \mathrm{G} 12 \mathrm{mAb}$ resistance [18] and these observations indicate that comparable resistance mutations for $2 \mathrm{G} 12 \mathrm{mAb}$ appear in different cell lines under prolonged exposure [22,85]. When both CBAs were given simultaneously for longer periods to induce resistance, three mutations appeared in gp120 (N160, N339 and N386) and remarkably also one in gp41 (N672), together with the induced glycan at N162 [85]. The three mutations observed in HHA/2G12 mAb combination-arm, were also found in the single HHA-selected strain. It was assumed that HIV-1 
exposure to paired CBA combinations with different binding sites will make it more difficult for the virus to escape drug pressure. This will result in marked decrease of resistance development and a lower mutation rate [85]. In depth cross-resistance studies demonstrated that the presence of this "potential" complex N-glycan site deletion in gp41, due to the asparagine to aspartate mutation at position N672 (N672D), resulted in higher levels of resistance against the CBAs AH, HHA and GNA compared to strains lacking this specific mutation [85]. As mentioned above, Huskens et al. [22] reported an increased susceptibility of the NL4.3 2G12mAb-resistant HIV-1 strain, carrying only the N295 mutation, for various CBAs (Table 2). Surprisingly, the NL4.3 variant, generated by Mathys and Balzarini, had also only one mutation, the N392 deletion, but showed no increased potency of CBAs [85]. The NL4.3 ${ }^{2 \mathrm{G} 12 \mathrm{res}}$ HIV-1 strain demonstrated solely resistance to $2 \mathrm{G} 12 \mathrm{mAb}$ (>57-fold), while the NL4.3 ${ }^{\text {HHAres }} \mathrm{HIV}-1$ strain showed high levels ( $>35$-fold) of (cross-)resistance against HHA, 2 G12 mAb and GNA. Less than 10-fold cross-resistance was noticed against AH and UDA. The HIV-1 NL4.3 ${ }^{\mathrm{HHA} / 2 \mathrm{G} 12 \mathrm{res}}$ strain carrying also the N672D mutation showed cross-resistance against HHA (16-fold), GNA (10-fold), 2G12 mAb ( $>50$-fold), AH and UDA (both 2-fold) [85]. Viral infectivity studies, as measured by p24 Ag levels, indicated a significant difference between the resistant (p24 Ag: $\leq 14 \times 10^{4} \mathrm{pg} / \mathrm{mL}$ ) and wild-type HIV-1 strains (p24 Ag: $30 \times 10^{4} \mathrm{pg} / \mathrm{mL}$ ). The HHA/2G12mAb mutated strains showed comparable amounts of $\mathrm{p} 24 \mathrm{Ag}$ concentrations as their single resistant strains [85].

CBA pressure selects HIV-1 resistant strains that have preferably high-mannose type N-linked glycans annihilated (Table 1). Of the six "potential" complex glycans sites (N136, N141, N156, N160, N186 and N197) present in the V1/V2 loop: the N141, N156 and N197 have never been mutated so far. However, our BanLec-resistant HIV-1 IIIB strain created a novel sequon at position 142 by mutating serine to asparagine (S142N) (Table 1; Figure 1B). A thorough investigation on the effect on glycan deletions on the V1/V2 loop of gp120 showed in some cases high compromised viral infectivity and replication rates, but an increased susceptibility of these mutated strains for certain CBAs such as the plant lectins HHA and UDA [86]. Positions assigned to be complex type glycans are most likely recognized by glycan-reactive broad-neutralizing antibodies with a documented complex-type glycan binding ability such as PG9 and PG16. These antibodies recognize Man $5 \mathrm{GlcNAc}_{2}$ structure at position N160 and a sialylated complex $N$-linked glycan at position N156 [87]. The high-mannose glycan site N332 was found to be critical for the binding of PGT121. Glycan array and crystal structure studies also reported an interaction of this antibody with a putative V1/V2 bi-antennary complex glycan $[88,89]$. These data indicate also the necessity of the presence of complex glycans for optimal neutralizing activity by antibodies.

The N241, N262 and N356 sites on gp120 (which corresponds to N239, N260 and N354 in NL4.3 sequences [Figure 1B]) were never found to be mutated under prolonged CBA pressure (Table 1 and Figure 2) [90]; not even in the presence of two CBAs simultaneously [85]. Of these three glycans, the highly conserved N262 seems indispensable for viral entry and infectivity as shown by site-directed mutagenesis studies [51,90,91]. The N262Q mutation affects the folding and lysosomal degradation of gp120 [92]. Remarkably, the glycine at position 263 (or 261 for NL4.3) of this sequon (262NGS264) is also highly conserved among various HIV-1 strains and mutating this amino acid to an alanine results in a lower infectivity rate [90]. These findings demonstrate the importance of this highly conserved glycan and represent a potential "hot spot" for antiviral therapy. 
A healthy vaginal microbiota, which is dominated by Lactobacillus species, play an important role in the protection of women for HIV transmission and infection by: $(i)$ the direct/indirect production of antiviral components (e.g., bacteriocins, hydrogen peroxide and lactic acid), (ii) by stimulating the immune system and (iii) by lectin-mediated binding mechanisms [93]. This indicates that the class of CBAs may not harm the endogenous vaginal flora. Tsai and coworkers could clearly demonstrate that a CV-N gel protected 15 of 18 female macaques (Macaca fascicularis) from SHIV89.6P (simian/human immunodeficiency virus) infection after vaginal challenge [94]. They also found that CV-N was able to prevent rectal SHIV89.6P transmission in male macaques [95]. On the other hand, live recombinant Lactobacilli expressing CV-N could reduce vaginal SHIV transmission in macaques by 63\% [96]. Later studies demonstrated that addition of these CV-N-expressing Lactobacilli neither changed the diversity of the vaginal microbiota, nor triggered pro-inflammatory changes to the local mucosa [97]. These data are very promising and suggest that Lactobacilli expressing CBAs can be used as "live-microbicides" to prevent HIV transmission and subsequent infections. In collaborative studies, we were able to express the CBAs AH and GRFT in certain Lactobacilli strains, however they could not be secreted due to unknown parameters (unpublished results). These data clearly indicate that not each CBA can be used as a "live-microbicide". Each potential candidate should be thoroughly examined, as the class of CBAs are a diverse group of proteins with widely differing properties.

It is generally accepted that CBAs have a very low, if any, oral bioavailability. As described above, most in vivo research of antiviral active CBAs was performed in pre-exposure prophylaxis models [94,95]. More recently, different studies in murine models indicate that CBAs could also be used as antiviral therapy. A significant survival rate was observed when CV-N was given intranasally as prophylactic agent or at early initiation of treatment (within $6 \mathrm{~h}$ post-infection) in an influenza model [98]. Regarding the current Ebola virus outbreaks in several african countries (e.g., Liberia, Guinea and Sierra Leone) [99], the severity of Ebola infections in mice was shown to be reduced by CV-N treatment [100]. However, therapy with high doses of mannose-binding lectin (MBL), a component of the innate immune system, also diminished the Ebola infections in murine models [101]. Such findings open novel perspectives for the class of CBAs as even therapeutic agents. Beyond the scope of this review, but important to mention is that many CBAs have besides anti-HIV activity also a potent inactivating profile against other viruses, of which some are currently hard to treat or untreatable like Herpes simplex virus (HSV), Dengue virus, Ebola virus and/or Hepatitis C virus (HCV) [100,102-104]. However, their potent and mainly consistent antiviral activity, in this context against HIV, can sometimes be overshadowed by mitogenic and/or cell-agglutinating properties of certain CBAs.

$\mathrm{CV}-\mathrm{N}$ is one of the most extensively studied CBA so far. Despite its potent broad antiviral activity, confusing data are found regarding toxicity and mitogenicity $[42,49,50,105]$. Buffa and colleagues found no cytoxicity of CV-N in PBMCs and cervical tissue explants ( $\mathrm{IC}_{50} \geq 0.45 \mathrm{mM}$ ). Low mitogenic activity was seen following three days of $\mathrm{CV}-\mathrm{N}$ exposure, which could be greatly diminished when it was reduced to $2 \mathrm{~h}$ followed by three days of culture [50]. On the other hand, previous studies indicated pronounced mitogenic effects in PBMCs after pre-exposure of low sub-inhibitory CV-N concentrations, as increased viral replication values, compared to untreated conditions, were observed. This resulted in a higher susceptibility for R5 HIV-1 replication. In addition, increased levels of T cell activation markers [CD69 (early), CD25 (late) and HLA-DR (very late)] and of various pro-inflammatory cytokines were measured $[49,105]$. These potential side effects are probably unrelated to its carbohydrate-binding 
activity. Various other CBAs seem devoided of such cytotoxic and mitogenic properties. Safety studies using AH, HHA, GNA, UDA, GRFT and MVN demonstrated no upregulation of these T cell activation markers, nor significant induction of pro-inflammatory cytokines and chemokines [26,29,105,106]. In addition, GRFT, HHA and GNA did not show hemagglutination activity on human erythrocytes [32,107]. On the other hand, MVN can be a very good alternative for CV-N as microbicidal agent, as both molecules share 33\% identity at the amino acid level [52]. MVN has a comparable anti-HIV-1 activity, with exception for HIV-2 and HIV-1 group O isolates. However, it is 50-fold less toxic and showed a much better safety profile than CV-N [26].

A thorough investigation also demonstrated that both GRFT and CV-N were able to interact with the cervical epithelial cells [106]. Distinct differences in their binding patterns were seen, as CV-N bound much more extensively throughout several layers of the cervical epithelium. The binding to the cell surface was significantly reduced when the sugar-binding sites were occupied with yeast mannan, while only partial reducing binding effects were seen for CV-N. This implies secondary binding mechanisms between CV-N and the cell surface. Remarkably, when the PBMCs were pre-treated for $24 \mathrm{~h}$ with GRFT or CV-N, subsequently washed and infected with R5 HIV-1 in the absence of these lectins, a potent inhibition of viral infection was observed for GRFT at a concentration of $0.13 \mathrm{nM}$, while CV-N at $182 \mathrm{nM}$ significantly increased viral replication $[26,106]$.

Follow-up safety studies by Barton and coworkers demonstrated that GRFT, when given subcutaneously to mice and guinea pigs, was present in concentrations well above its $\mathrm{IC}_{50}$-value and remained in plasma and serum for many days. In addition, GRFT accumulated in tissues like the spleen, kidney and liver. Organ weight investigation did suggest a nascent immune response to GRFT, but no antibodies were detected. GRFT did not alter animal behavior and no animals died due to treatment [107]. These optimistic data indicate that de-immunizing this molecule may be necessary for long-term treatment. At the moment, computational methods (e.g., EpiSweep) are available that produce designs of therapeutic proteins with preserved structural properties and minimal $T$ cell epitopes $[108,109]$, however further investigation of their production, antiviral and immunological properties are needed.

Overall, these data show that CBAs can have potential in the prophylaxis (microbicide) and treatment of (chronic) viral infections such as HIV.

\section{Acknowledgments}

The authors would like to thank Sandra Claes, Rebecca Provinciael, Evelyne Van Kerckhove, Eric Fonteyn and Yoeri Schrooten for excellent technical assistance and Kristel Van Laethem for dedicated help with the sequence analysis. This work was supported by the KU Leuven (GOA 10/014, PF/10/018), the Foundation of Scientific Research (FWO No. G-0485-08, G-0528-12), the Foundation Dormeur, Vaduz and the CHAARM project (No. 242135) of the European Commission.

\section{Conflicts of Interest}

The authors declare no conflict of interest. 


\section{References}

1. Wilen, C.B.; Tilton, J.C.; Doms, R.W. HIV: Cell binding and entry. Cold Spring Harb. Perspect Med. 2012, 2, doi:10.1101/cshperspect.a006866.

2. Miyauchi, K.; Kim, Y.; Latinovic, O.; Morozov, V.; Melikyan, G.B. HIV enters cells via endocytosis and dynamin-dependent fusion with endosomes. Cell 2009, 137, 433-444.

3. Leonard, C.K.; Spellman, M.W.; Riddle, L.; Harris, R.J.; Thomas, J.N.; Gregory, T.J. Assignment of intrachain disulfide bonds and characterization of potential glycosylation sites of the type 1 recombinant human immunodeficiency virus envelope glycoprotein (gp120) expressed in chinese hamster ovary cells. J. Biol. Chem. 1990, 265, 10373-10382.

4. Scanlan, C.N.; Offer, J.; Zitzmann, N.; Dwek, R.A. Exploiting the defensive sugars of HIV-1 for drug and vaccine design. Nature 2007, 446, 1038-1045.

5. Helenius, A.; Aebi, M. Intracellular functions of n-linked glycans. Science 2001, 291, 2364-2369.

6. Mizuochi, T.; Spellman, M.W.; Larkin, M.; Solomon, J.; Basa, L.J.; Feizi, T. Structural characterization by chromatographic profiling of the oligosaccharides of human immunodeficiency virus (HIV) recombinant envelope glycoprotein gp120 produced in chinese hamster ovary cells. Biomed. Chromatogr. 1988, 2, 260-270.

7. Mizuochi, T.; Spellman, M.W.; Larkin, M.; Solomon, J.; Basa, L.J.; Feizi, T. Carbohydrate structures of the human-immunodeficiency-virus (HIV) recombinant envelope glycoprotein gp120 produced in chinese-hamster ovary cells. Biochem. J. 1988, 254, 599-603.

8. Doores, K.J.; Bonomelli, C.; Harvey, D.J.; Vasiljevic, S.; Dwek, R.A.; Burton, D.R.; Crispin, M.; Scanlan C.N. Envelope glycans of immunodeficiency virions are almost entirely oligomannose antigens. Proc. Natl. Acad. Sci. USA 2010, 107, 13800-13805.

9. Bonomelli, C.; Doores, K.J.; Dunlop, D.C.; Thaney, V.; Dwek, R.A.; Burton, D.R.; Crispin, M.; Scanlan, C.N. The glycan shield of HIV is predominantly oligomannose independently of production system or viral clade. PLoS One 2011, 6, e23521.

10. Weis, W.I.; Taylor, M.E.; Drickamer, K. The c-type lectin superfamily in the immune system. Immunol. Rev. 1998, 163, 19-34.

11. Kwong, P.D.; Wyatt, R.; Robinson, J.; Sweet, R.W.; Sodroski, J.; Hendrickson, W.A. Structure of an HIV gp120 envelope glycoprotein in complex with the cd4 receptor and a neutralizing human antibody. Nature 1998, 393, 648-659.

12. Balzarini, J. Targeting the glycans of glycoproteins: A novel paradigm for antiviral therapy. Nat. Rev. Microbiol. 2007, 5, 583-597.

13. Van Liempt, E.; Bank, C.M.; Mehta, P.; Garcia-Vallejo, J.J.; Kawar, Z.S.; Geyer, R.; Alvarez, R.A.; Cummings, R.D.; van Kooyk, Y.; van Die, I. Specificity of dc-sign for mannose- and fucose-containing glycans. FEBS Lett. 2006, 580, 6123-6131.

14. Van Kooyk, Y.; Geijtenbeek, T.B. DC-SIGN: Escape mechanism for pathogens. Nat. Rev. Immunol. 2003, 3, 697-709.

15. Cavrois, M.; Neidleman, J.; Greene, W.C. The achilles heel of the trojan horse model of HIV-1 trans-infection. PLoS Pathog. 2008, 4, e1000051. 
16. Buchacher, A.; Predl, R.; Strutzenberger, K.; Steinfellner, W.; Trkola, A.; Purtscher, M.; Gruber, G.; Tauer, C.; Steindl, F.; Jungbauer, A.; et al. Generation of human monoclonal antibodies against HIV-1 proteins; electrofusion and epstein-barr virus transformation for peripheral blood lymphocyte immortalization. AIDS Res. Hum. Retrovir. 1994, 10, 359-369.

17. Trkola, A.; Purtscher, M.; Muster, T.; Ballaun, C.; Buchacher, A.; Sullivan, N.; Srinivasan, K.; Sodroski, J.; Moore, J.P.; Katinger, H. Human monoclonal antibody $2 \mathrm{~g} 12$ defines a distinctive neutralization epitope on the gp120 glycoprotein of human immunodeficiency virus type 1 . J. Virol. 1996, 70, 1100-1108.

18. Scanlan, C.N.; Pantophlet, R.; Wormald, M.R.; Ollmann Saphire, E.; Stanfield, R.; Wilson, I.A.; Katinger, H.; Dwek, R.A.; Rudd, P.M.; Burton, D.R. The broadly neutralizing anti-human immunodeficiency virus type 1 antibody $2 \mathrm{~g} 12$ recognizes a cluster of $\alpha 1 \rightarrow 2$ mannose residues on the outer face of gp120. J. Virol. 2002, 76, 7306-7321.

19. Wyatt, R.; Kwong, P.D.; Desjardins, E.; Sweet, R.W.; Robinson, J.; Hendrickson, W.A.; Sodroski, J.G. The antigenic structure of the HIV gp120 envelope glycoprotein. Nature 1998, 393, 705-711.

20. Calarese, D.A.; Scanlan, C.N.; Zwick, M.B.; Deechongkit, S.; Mimura, Y.; Kunert, R.; Zhu, P.; Wormald, M.R.; Stanfield, R.L.; Roux, K.H.; et al. Antibody domain exchange is an immunological solution to carbohydrate cluster recognition. Science 2003, 300, 2065-2071.

21. Trkola, A.; Pomales, A.B.; Yuan, H.; Korber, B.; Maddon, P.J.; Allaway, G.P.; Katinger, H.; Barbas, C.F., 3rd; Burton, D.R.; Ho, D.D.; et al. Cross-clade neutralization of primary isolates of human immunodeficiency virus type 1 by human monoclonal antibodies and tetrameric cd4-igg. J. Virol. 1995, 69, 6609-6617.

22. Huskens, D.; van Laethem, K.; Vermeire, K.; Balzarini, J.; Schols, D. Resistance of HIV-1 to the broadly HIV-1-neutralizing, anti-carbohydrate antibody 2g12. Virology 2007, 360, 294-304.

23. Férir, G.; Huskens, D.; Palmer, K.E.; Boudreaux, D.M.; Swanson, M.D.; Markovitz, D.M.; Balzarini, J.; Schols, D. Combinations of griffithsin with other carbohydrate-binding agents demonstrate superior activity against HIV type 1, HIV type 2, and selected carbohydrate-binding agent-resistant HIV type 1 strains. AIDS Res. Hum. Retrovir. 2012, 28, 1513-1523.

24. Sanders, R.W.; Venturi, M.; Schiffner, L.; Kalyanaraman, R.; Katinger, H.; Lloyd, K.O.; Kwong, P.D.; Moore, J.P. The mannose-dependent epitope for neutralizing antibody $2 \mathrm{~g} 12$ on human immunodeficiency virus type 1 glycoprotein gp120. J. Virol. 2002, 76, 7293-7305.

25. Chen, H.; Xu, X.; Bishop, A.; Jones, I.M. Reintroduction of the $2 \mathrm{~g} 12$ epitope in an HIV-1 clade c gp120. AIDS 2005, 19, 833-835.

26. Huskens, D.; Férir, G.; Vermeire, K.; Kehr, J.C.; Balzarini, J.; Dittmann, E.; Schols, D. Microvirin, a novel \{alpha\}(1,2)-mannose-specific lectin isolated from microcystis aeruginosa, has comparable anti-HIV-1 activity as cyanovirin-n, but a much higher safety profile. J. Biol. Chem. 2010, 285, $24845-24854$.

27. Férir, G.; Huskens, D.; Noppen, S.; Koharudin, L.M.; Gronenborn, A.M.; Schols, D. Broad anti-HIV activity of the oscillatoria agardhii agglutinin homologue lectin family. J. Antimicrob. Chemother. 2014, 69, 2746-2758.

28. Kaku, H.; van Damme, E.J.; Peumans, W.J.; Goldstein, I.J. Carbohydrate-binding specificity of the daffodil (Narcissus pseudonarcissus) and amaryllis (Hippeastrum hybr.) bulb lectins. Arch. Biochem. Biophys. 1990, 279, 298-304. 
29. Hoorelbeke, B.; Huskens, D.; Férir, G.; François, K.; Takahashi, A.; van Laethem, K.; Schols, D.; Tanaka, H.; Balzarini, J. Actinohivin, a broadly neutralizing prokaryotic lectin, inhibits HIV-1 infection by specically targeting high-mannose-type glycans on the gp120 envelope. Antimicrob. Agents Chemother. 2010, 54, 3287-3301.

30. Férir, G.; Vermeire, K.; Huskens, D.; Balzarini, J.; van Damme, E.J.; Kehr, J.C.; Dittmann, E.; Swanson, M.D.; Markovitz, D.M.; Schols, D. Synergistic in vitro anti-HIV type 1 activity of tenofovir with carbohydrate-binding agents (cbas). Antivir. Res. 2011, 90, 200-204.

31. Pollicita, M.; Schols, D.; Aquaro, S.; Peumans, W.J.; van Damme, E.J.; Perno, C.F.; Balzarini, J. Carbohydrate-binding agents (cbas) inhibit HIV-1 infection in human primary monocyte-derived macrophages (mdms) and efficiently prevent mdm-directed viral capture and subsequent transmission to cd4+ t lymphocytes. Virology 2008, 370, 382-391.

32. Balzarini, J.; Hatse, S.; Vermeire, K.; Princen, K.; Aquaro, S.; Perno, C.F.; de Clercq, E.; Egberink, H.; Vanden Mooter, G.; Peumans, W.; et al. Mannose-specific plant lectins from the amaryllidaceae family qualify as efficient microbicides for prevention of human immunodeficiency virus infection. Antimicrob. Agents Chemother. 2004, 48, 3858-3870.

33. Balzarini, J.; Schols, D.; Neyts, J.; van Damme, E.; Peumans, W.; de Clercq, E. Alpha-(1-3)- and alpha-(1-6)-d-mannose-specific plant lectins are markedly inhibitory to human immunodeficiency virus and cytomegalovirus infections in vitro. Antimicrob. Agents Chemother. 1991, 35, 410-416.

34. Balzarini, J.; van Laethem, K.; Hatse, S.; Froeyen, M.; Peumans, W.; van Damme, E.; Schols, D. Carbohydrate-binding agents cause deletions of highly conserved glycosylation sites in HIV gp120: A new therapeutic concept to hit the achilles heel of HIV. J. Biol. Chem. 2005, 280, 41005-41014.

35. Balzarini, J.; van Laethem, K.; Hatse, S.; Froeyen, M.; van Damme, E.; Bolmstedt, A.; Peumans, W.; de Clercq, E.; Schols, D. Marked depletion of glycosylation sites in HIV-1 gp120 under selection pressure by the mannose-specific plant lectins of hippeastrum hybrid and galanthus nivalis. Mol. Pharmacol. 2005, 67, 1556-1565.

36. Shibuya, N.; Goldstein, I.J.; van Damme, E.J.; Peumans, W.J. Binding properties of a mannose-specific lectin from the snowdrop (galanthus nivalis) bulb. J. Biol. Chem. 1988, 263, 728-734.

37. Chiba, H.; Inokoshi, J.; Okamoto, M.; Asanuma, S.; Matsuzaki, K.; Iwama, M.; Mizumoto, K.; Tanaka, H.; Oheda, M.; Fujita, K.; et al. Actinohivin, a novel anti-HIV protein from an actinomycete that inhibits syncytium formation: Isolation, characterization, and biological activities. Biochem. Biophys. Res. Commun. 2001, 282, 595-601.

38. Tanaka, H.; Chiba, H.; Inokoshi, J.; Kuno, A.; Sugai, T.; Takahashi, A.; Ito, Y.; Tsunoda, M.; Suzuki, K.; Takenaka, A.; et al. Mechanism by which the lectin actinohivin blocks HIV infection of target cells. Proc. Natl. Acad. Sci. USA 2009, 106, 15633-15638.

39. Takahashi, A.; Inokoshi, J.; Hachiya, A.; Oka, S.; Omura, S.; Tanaka, H. The high mannose-type glycan binding lectin actinohivin: Dimerization greatly improves anti-HIV activity. J. Antibiot. (Tokyo) 2011, 64, 551-557.

40. Takahashi, A.; Inokoshi, J.; Tsunoda, M.; Suzuki, K.; Takenaka, A.; Sekiguchi, T.; Omura, S.; Tanaka, H. Actinohivin: Specific amino acid residues essential for anti-HIV activity. J. Antibiot. (Tokyo) 2010, 63, 661-665. 
41. Chiba, H.; Inokoshi, J.; Nakashima, H.; Omura, S.; Tanaka, H. Actinohivin, a novel anti-human immunodeficiency virus protein from an actinomycete, inhibits viral entry to cells by binding high-mannose type sugar chains of gp120. Biochem. Biophys. Res. Commun. 2004, 316, 203-210.

42. Boyd, M.R.; Gustafson, K.R.; McMahon, J.B.; Shoemaker, R.H.; O'Keefe, B.R.; Mori, T.; Gulakowski, R.J.; Wu, L.; Rivera, M.I.; Laurencot, C.M.; et al. Discovery of cyanovirin-n, a novel human immunodeficiency virus-inactivating protein that binds viral surface envelope glycoprotein gp120: Potential applications to microbicide development. Antimicrob. Agents Chemother. 1997, $41,1521-1530$.

43. Bewley, C.A.; Gustafson, K.R.; Boyd, M.R.; Covell, D.G.; Bax, A.; Clore, G.M.; Gronenborn, A.M. Solution structure of cyanovirin-N, a potent HIV-inactivating protein. Nat. Struct. Biol. 1998, 5, 571-578.

44. Yang, F.; Bewley, C.A.; Louis, J.M.; Gustafson, K.R.; Boyd, M.R.; Gronenborn, A.M.; Clore, G.M.; Wlodawer, A. Crystal structure of cyanovirin-N, a potent HIV-inactivating protein, shows unexpected domain swapping. J. Mol. Biol. 1999, 288, 403-412.

45. Barrientos, L.G.; Louis, J.M.; Botos, I.; Mori, T.; Han, Z.; O’Keefe, B.R.; Boyd, M.R.; Wlodawer, A.; Gronenborn, A.M. The domain-swapped dimer of cyanovirin-N is in a metastable folded state: Reconciliation of X-ray and nmr structures. Structure 2002, 10, 673-686.

46. Bewley, C.A.; Otero-Quintero, S. The potent anti-HIV protein cyanovirin-n contains two novel carbohydrate binding sites that selectively bind to $\operatorname{man}(8) \mathrm{d} 1 \mathrm{~d} 3$ and $\operatorname{man}(9)$ with nanomolar affinity: Implications for binding to the HIV envelope protein gp120. J. Am. Chem. Soc. 2001, 123, 3892-3902.

47. Shenoy, S.R.; O’Keefe, B.R.; Bolmstedt, A.J.; Cartner, L.K.; Boyd, M.R. Selective interactions of the human immunodeficiency virus-inactivating protein cyanovirin-n with high-mannose oligosaccharides on gp120 and other glycoproteins. J. Pharmacol. Exp. Ther. 2001, 297, 704-710.

48. Botos, I.; O'Keefe, B.R.; Shenoy, S.R.; Cartner, L.K.; Ratner, D.M.; Seeberger, P.H.; Boyd, M.R.; Wlodawer, A. Structures of the complexes of a potent anti-HIV protein cyanovirin-N and high mannose oligosaccharides. J. Biol. Chem. 2002, 277, 34336-34342.

49. Balzarini, J.; van Laethem, K.; Peumans, W.J.; van Damme, E.J.; Bolmstedt, A.; Gago, F.; Schols, D. Mutational pathways, resistance profile, and side effects of cyanovirin relative to human immunodeficiency virus type 1 strains with $\mathrm{N}$-glycan deletions in their gp120 envelopes. J. Virol. 2006, 80, 8411-8421.

50. Buffa, V.; Stieh, D.; Mamhood, N.; Hu, Q.; Fletcher, P.; Shattock, R.J. Cyanovirin-N potently inhibits human immunodeficiency virus type 1 infection in cellular and cervical explant models. J. Gen. Virol. 2009, 90, 234-243.

51. Hu, Q.; Mahmood, N.; Shattock, R.J. High-mannose-specific deglycosylation of HIV-1 gp120 induced by resistance to cyanovirin-N and the impact on antibody neutralization. Virology 2007, $368,145-154$.

52. Kehr, J.C.; Zilliges, Y.; Springer, A.; Disney, M.D.; Ratner, D.D.; Bouchier, C.; Seeberger, P.H.; de Marsac, N.T.; Dittmann, E. A mannan binding lectin is involved in cell-cell attachment in a toxic strain of microcystis aeruginosa. Mol. Microbiol. 2006, 59, 893-906. 
53. Shahzad-ul-Hussan, S.; Gustchina, E.; Ghirlando, R.; Clore, G.M.; Bewley, C.A. Solution structure of the monovalent lectin microvirin in complex with man(alpha)(1-2)man provides a basis for anti-HIV activity with low toxicity. J. Biol. Chem. 2011, 286, 20788-20796.

54. Koshte, V.L.; van Dijk, W.; van der Stelt, M.E.; Aalberse, R.C. Isolation and characterization of banlec-I, a mannoside-binding lectin from musa paradisiac (banana). Biochem. J. 1990, 272, 721-726.

55. Peumans, W.J.; Zhang, W.; Barre, A.; Houles Astoul, C.; Balint-Kurti, P.J.; Rovira, P.; Rouge, P.; May, G.D.; van Leuven, F.; Truffa-Bachi, P.; et al. Fruit-specific lectins from banana and plantain. Planta 2000, 211, 546-554.

56. Meagher, J.L.; Winter, H.C.; Ezell, P.; Goldstein, I.J.; Stuckey, J.A. Crystal structure of banana lectin reveals a novel second sugar binding site. Glycobiology 2005, 15, 1033-1042.

57. Mo, H.; Winter, H.C.; van Damme, E.J.; Peumans, W.J.; Misaki, A.; Goldstein, I.J. Carbohydrate binding properties of banana (musa acuminata) lectin I. Novel recognition of internal alpha1,3-linked glucosyl residues. Eur. J. Biochem. 2001, 268, 2609-2615.

58. Goldstein, I.J.; Winter, H.C.; Mo, H.; Misaki, A.; van Damme, E.J.; Peumans, W.J. Carbohydrate binding properties of banana (musa acuminata) lectin II. Binding of laminaribiose oligosaccharides and beta-glucans containing beta1,6-glucosyl end groups. Eur. J. Biochem. 2001, 268, 2616-2619.

59. Swanson, M.D.; Winter, H.C.; Goldstein, I.J.; Markovitz, D.M. A lectin isolated from bananas is a potent inhibitor of HIV replication. J. Biol. Chem. 2010, 285, 8646-8655.

60. Férir, G.; Palmer, K.E.; Schols, D. Griffithsin, alone and combined with all classes of antiretroviral drugs, potently inhibits HIV cell-cell transmission and destruction of cd4 $+\mathrm{t}$ cells. J. Antivir. Antiretrovir. 2012, 4, 103-112.

61. Mori, T.; O’Keefe, B.R.; Sowder, R.C., 2nd; Bringans, S.; Gardella, R.; Berg, S.; Cochran, P.; Turpin, J.A.; Buckheit, R.W., Jr.; McMahon, J.B.; et al. Isolation and characterization of griffithsin, a novel HIV-inactivating protein, from the red alga Griffithsia sp. J. Biol. Chem. 2005, 280, 9345-9353.

62. Ziółkowska, N.E.; O’Keefe, B.R.; Mori, T.; Zhu, C.; Giomarelli, B.; Vojdani, F.; Palmer, K.E.; McMahon, J.B.; Wlodawer, A. Domain-swapped structure of the potent antiviral protein griffithsin and its mode of carbohydrate binding. Structure 2006, 14, 1127-1135.

63. Ziółkowska, N.E.; Shenoy, S.R.; O’Keefe, B.R.; Wlodawer, A. Crystallographic studies of the complexes of antiviral protein griffithsin with glucose and N-acetylglucosamine. Protein Sci. 2007, $16,1485-1489$.

64. Ziółkowska, N.E.; Shenoy, S.R.; O’Keefe, B.R.; McMahon, J.B.; Palmer, K.E.; Dwek, R.A.; Wormald, M.R.; Wlodawer, A. Crystallographic, thermodynamic, and molecular modeling studies of the mode of binding of oligosaccharides to the potent antiviral protein griffithsin. Proteins $\mathbf{2 0 0 7}$, 67, 661-670.

65. Moulaei, T.; Shenoy, S.R.; Giomarelli, B.; Thomas, C.; McMahon, J.B.; Dauter, Z.; O’Keefe, B.R.; Wlodawer, A. Monomerization of viral entry inhibitor griffithsin elucidates the relationship between multivalent binding to carbohydrates and anti-HIV activity. Structure 2010, 18, 1104-1115.

66. Xue, J.; Hoorelbeke, B.; Kagiampakis, I.; Demeler, B.; Balzarini, J.; Liwang, P.J. The griffithsin dimer is required for high-potency inhibition of HIV-1: Evidence for manipulation of the structure of gp120 as part of the griffithsin dimer mechanism. Antimicrob. Agents Chemother. 2013, 57, 3976-3989. 
67. Emau, P.; Tian, B.; O’Keefe B, R.; Mori, T.; McMahon, J.B.; Palmer, K.E.; Jiang, Y.; Bekele, G.; Tsai, C.C. Griffithsin, a potent hiv entry inhibitor, is an excellent candidate for anti-HIV microbicide. J. Med. Primatol. 2007, 36, 244-253.

68. Huang, X.; Jin, W.; Griffin, G.E.; Shattock, R.J.; Hu, Q. Removal of two high-mannose N-linked glycans on gp120 renders human immunodeficiency virus 1 largely resistant to the carbohydrate-binding agent griffithsin. J. Gen. Virol. 2011, 92, 2367-2373.

69. Alexandre, K.B.; Gray, E.S.; Lambson, B.E.; Moore, P.L.; Choge, I.A.; Mlisana, K.; Karim, S.S.; McMahon, J.; O'Keefe, B.; Chikwamba, R.; et al. Mannose-rich glycosylation patterns on HIV-1 subtype c gp120 and sensitivity to the lectins, griffithsin, cyanovirin-N and scytovirin. Virology 2010, 402, 187-196.

70. Férir, G.; Palmer, K.E.; Schols, D. Synergistic activity profile of griffithsin in combination with tenofovir, maraviroc and enfuvirtide against HIV-1 clade c. Virology 2011, 417, 253-258.

71. Hoorelbeke, B.; Xue, J.; LiWang, P.J.; Balzarini, J. Role of the carbohydrate-binding sites of griffithsin in the prevention of dc-sign-mediated capture and transmission of HIV-1. PLoS One 2013, 8, e64132.

72. Sato, Y.; Murakami, M.; Miyazawa, K.; Hori, K. Purification and characterization of a novel lectin from a freshwater cyanobacterium, oscillatoria agardhii. Comp. Biochem. Physiol. B Biochem. Mol. Biol. 2000, 125, 169-177.

73. Sato, Y.; Okuyama, S.; Hori, K. Primary structure and carbohydrate binding specificity of a potent anti-HIV lectin isolated from the filamentous cyanobacterium oscillatoria agardhii. J. Biol. Chem. 2007, 282, 11021-11029.

74. Koharudin, L.M.; Gronenborn, A.M. Structural basis of the anti-HIV activity of the cyanobacterial oscillatoria agardhii agglutinin. Structure 2011, 19, 1170-1181.

75. Shibuya, N.; Goldstein, I.J.; Shafer, J.A.; Peumans, W.J.; Broekaert, W.F. Carbohydrate binding properties of the stinging nettle (urtica dioica) rhizome lectin. Arch. Biochem. Biophys. 1986, 249, 215-224.

76. Peumans, W.; de Ley, M.; Broekaert, W.F. An unusual lectin from stinging nettle (urtica dioica) rhizomes. FEBS Lett. 1984, 177, 99-103.

77. Balzarini, J.; Neyts, J.; Schols, D.; Hosoya, M.; van Damme, E.; Peumans, W.; de Clercq, E. The mannose-specific plant lectins from cymbidium hybrid and epipactis helleborine and the (N-acetylglucosamine)n-specific plant lectin from urtica dioica are potent and selective inhibitors of human immunodeficiency virus and cytomegalovirus replication in vitro. Antiviral Res. 1992, 18, 191-207.

78. Gordts, S.C.; Renders, M.; Férir, G.; Huskens, D.; van Damme, E.; Peumans, W.; Balzarini, J.; Schols, D. Nictaba and uda, two glcnac-binding lectins with unique anti-viral activity profile. J. Antimicrob. Chemother. 2014, submitted.

79. Chen, Y.; Peumans, W.J.; Hause, B.; Bras, J.; Kumar, M.; Proost, P.; Barre, A.; Rouge, P.; van Damme, E.J. Jasmonic acid methyl ester induces the synthesis of a cytoplasmic/nuclear chito-oligosaccharide binding lectin in tobacco leaves. FASEB J. 2002, 16, 905-907.

80. Lannoo, N.; van Damme, E.J. Expression analysis of jasmonate-responsive lectins in plants. Methods Mol. Biol. 2013, 1011, 251-263. 
81. Schouppe, D.; Ghesquiere, B.; Menschaert, G.; de Vos, W.H.; Bourque, S.; Trooskens, G.; Proost, P.; Gevaert, K.; van Damme, E.J. Interaction of the tobacco lectin with histone proteins. Plant Physiol. 2011, 155, 1091-1102.

82. Lannoo, N.; Peumans, W.J.; Pamel, E.V.; Alvarez, R.; Xiong, T.C.; Hause, G.; Mazars, C.; van Damme, E.J. Localization and in vitro binding studies suggest that the cytoplasmic/nuclear tobacco lectin can interact in situ with high-mannose and complex N-glycans. FEBS Lett. 2006, 580, 6329-6337.

83. Abdool Karim, Q.; Abdool Karim, S.S.; Frohlich, J.A.; Grobler, A.C.; Baxter, C.; Mansoor, L.E.; Kharsany, A.B.; Sibeko, S.; Mlisana, K.P.; Omar, Z.; et al. Effectiveness and safety of tenofovir gel, an antiretroviral microbicide, for the prevention of HIV infection in women. Science $\mathbf{2 0 1 0}$, $329,1168-1174$.

84. Reitter, J.N.; Means, R.E.; Desrosiers, R.C. A role for carbohydrates in immune evasion in aids. Nat. Med. 1998, 4, 679-684.

85. Mathys, L.; Balzarini, J. Exposure of HIV-1 to a combination of two carbohydrate-binding agents markedly delays drug resistance development and selects for virus strains with compromised fitness. J. Antimicrob. Chemother. 2014, 69, 582-593.

86. Auwerx, J.; François, K.O.; Covens, K.; van Laethem, K.; Balzarini, J. Glycan deletions in the HIV-1 gp120 v1/v2 domain compromise viral infectivity, sensitize the mutant virus strains to carbohydrate-binding agents and represent a specific target for therapeutic intervention. Virology 2008, 382, 10-19.

87. Amin, M.N.; McLellan, J.S.; Huang, W.; Orwenyo, J.; Burton, D.R.; Koff, W.C.; Kwong, P.D.; Wang, L.X. Synthetic glycopeptides reveal the glycan specificity of HIV-neutralizing antibodies. Nat. Chem. Biol. 2013, 9, 521-526.

88. Julien, J.P.; Sok, D.; Khayat, R.; Lee, J.H.; Doores, K.J.; Walker, L.M.; Ramos, A.; Diwanji, D.C.; Pejchal, R.; Cupo, A.; et al. Broadly neutralizing antibody pgt121 allosterically modulates cd4 binding via recognition of the HIV-1 gp120 v3 base and multiple surrounding glycans. PLoS Pathog. 2013, 9, e1003342.

89. Mouquet, H.; Scharf, L.; Euler, Z.; Liu, Y.; Eden, C.; Scheid, J.F.; Halper-Stromberg, A.; Gnanapragasam, P.N.P.; Spencer, D.I.R.; Seaman, M.S.; et al. Complex-type N-glycan recognition by potent broadly neutralizing HIV antibodies. Proc. Natl. Acad. Sci. USA 2012, 109, E3268-E3277.

90. François, K.O.; Balzarini, J. The highly conserved glycan at asparagine 260 of HIV-1 gp120 is indispensable for viral entry. J. Biol. Chem. 2011, 286, 42900-42910.

91. Willey, R.L.; Smith, D.H.; Lasky, L.A.; Theodore, T.S.; Earl, P.L.; Moss, B.; Capon, D.J.; Martin, M.A. In vitro mutagenesis identifies a region within the envelope gene of the human immunodeficiency virus that is critical for infectivity. J. Virol. 1988, 62, 139-147.

92. Mathys, L.; François, K.O.; Quandte, M.; Braakman, I.; Balzarini, J. Deletion of the highly conserved n-glycan at asn260 of HIV-1 gp120 affects folding and lysosomal degradation of gp120, and results in loss of viral infectivity. PLoS One 2014, 9, e101181.

93. Petrova, M.I.; van den Broek, M.; Balzarini, J.; Vanderleyden, J.; Lebeer, S. Vaginal microbiota and its role in HIV transmission and infection. FEMS Microbiol. Rev. 2013, 37, 762-792. 
94. Tsai, C.C.; Emau, P.; Jiang, Y.; Agy, M.B.; Shattock, R.J.; Schmidt, A.; Morton, W.R.; Gustafson, K.R.; Boyd, M.R. Cyanovirin-N inhibits aids virus infections in vaginal transmission models. AIDS Res. Hum. Retrovir. 2004, 20, 11-18.

95. Tsai, C.C.; Emau, P.; Jiang, Y.; Tian, B.; Morton, W.R.; Gustafson, K.R.; Boyd, M.R. Cyanovirin-N gel as a topical microbicide prevents rectal transmission of shiv89.6p in macaques. AIDS Res. Hum. Retrovir. 2003, 19, 535-541.

96. Lagenaur, L.A.; Sanders-Beer, B.E.; Brichacek, B.; Pal, R.; Liu, X.; Liu, Y.; Yu, R.; Venzon, D.; Lee, P.P.; Hamer, D.H. Prevention of vaginal shiv transmission in macaques by a live recombinant lactobacillus. Mucosal Immunol. 2011, 4, 648-657.

97. Brichacek, B.; Lagenaur, L.A.; Lee, P.P.; Venzon, D.; Hamer, D.H. In vivo evaluation of safety and toxicity of a lactobacillus jensenii producing modified cyanovirin-n in a rhesus macaque vaginal challenge model. PLoS One 2013, 8, e 78817.

98. Smee, D.F.; Bailey, K.W.; Wong, M.H.; O’Keefe, B.R.; Gustafson, K.R.; Mishin, V.P.; Gubareva, L.V. Treatment of influenza a $(\mathrm{h} 1 \mathrm{n} 1)$ virus infections in mice and ferrets with cyanovirin-N. Antivir. Res. 2008, 80, 266-271.

99. Global Alert and Response (GAR). Available online: http://www.who.int/csr/disease/ebola/en/ (accessed on 23 September 2014).

100. Barrientos, L.G.; O'Keefe, B.R.; Bray, M.; Sanchez, A.; Gronenborn, A.M.; Boyd, M.R. Cyanovirin-N binds to the viral surface glycoprotein, gp1,2 and inhibits infectivity of ebola virus. Antivir. Res. 2003, 58, 47-56.

101. Michelow, I.C.; Lear, C.; Scully, C.; Prugar, L.I.; Longley, C.B.; Yantosca, L.M.; Ji, X.; Karpel, M.; Brudner, M.; Takahashi, K.; et al. High-dose mannose-binding lectin therapy for ebola virus infection. J. Infect. Dis. 2011, 203, 175-179.

102. Alen, M.M.; Kaptein, S.J.; de Burghgraeve, T.; Balzarini, J.; Neyts, J.; Schols, D. Antiviral activity of carbohydrate-binding agents and the role of dc-sign in dengue virus infection. Virology 2009, $387,67-75$.

103. Bertaux, C.; Daelemans, D.; Meertens, L.; Cormier, E.G.; Reinus, J.F.; Peumans, W.J.; van Damme, E.J.; Igarashi, Y.; Oki, T.; Schols, D.; et al. Entry of hepatitis c virus and human immunodeficiency virus is selectively inhibited by carbohydrate-binding agents but not by polyanions. Virology 2007, 366, 40-50.

104. Tiwari, V.; Shukla, S.Y.; Shukla, D. A sugar binding protein cyanovirin-N blocks herpes simplex virus type-1 entry and cell fusion. Antivir. Res. 2009, 84, 67-75.

105. Huskens, D.; Vermeire, K.; Vandemeulebroucke, E.; Balzarini, J.; Schols, D. Safety concerns for the potential use of cyanovirin-n as a microbicidal anti-HIV agent. Int. J. Biochem. Cell Biol. 2008, 40, 2802-2814.

106. Kouokam, J.C.; Huskens, D.; Schols, D.; Johannemann, A.; Riedell, S.K.; Walter, W.; Walker, J.M.; Matoba, N.; O'Keefe, B.R.; Palmer, K.E. Investigation of griffithsin's interactions with human cells confirms its outstanding safety and efficacy profile as a microbicide candidate. PLoS One 2011, 6, e22635. 
107. Barton, C.; Kouokam, J.C.; Lasnik, A.B.; Foreman, O.; Cambon, A.; Brock, G.; Montefiori, D.C.; Vojdani, F.; McCormick, A.A.; O'Keefe, B.R.; et al. Activity of and effect of subcutaneous treatment with the broad-spectrum antiviral lectin griffithsin in two laboratory rodent models. Antimicrob. Agents Chemother. 2014, 58, 120-127.

108. Parker, A.S.; Choi, Y.; Griswold, K.E.; Bailey-Kellogg, C. Structure-guided deimmunization of therapeutic proteins. J. Comput. Biol. 2013, 20, 152-165.

109. Choi, Y.; Griswold, K.E.; Bailey-Kellogg, C. Structure-based redesign of proteins for minimal T-cell epitope content. J. Comput. Chem. 2013, 34, 879-891.

(C) 2014 by the authors; licensee MDPI, Basel, Switzerland. This article is an open access article distributed under the terms and conditions of the Creative Commons Attribution license (http://creativecommons.org/licenses/by/4.0/). 